and Geotechnics

Elsevier Editorial System(tm) for Computers

Manuscript Draft

Manuscript Number: COGE-D-19-01135R1

Title: Mesoscopic time-dependent behavior of rocks based on threedimensional discrete element grain-based model

Article Type: Research Paper

Keywords: stress corrosion; Voronoi polyhedral; discrete element method; time-dependent behavior; brittle rocks

Corresponding Author: Professor Tao Xu, PhD

Corresponding Author's Institution: Northeastern University

First Author: Tengfei Fu

Order of Authors: Tengfei Fu; Tao Xu, PhD; Michael J Heap; Philip G. Meredith; Thomas M. Mitchell

Abstract: A three-dimensional discrete element grain-based stress corrosion model incorporating the theories of subcritical crack growth and chemical reaction rate was built to explore the time-dependent behavior of damage evolution and fracture patterns of brittle rocks on a mesoscopic scale. The model was first validated and the model accurately captured the evolution of damage (tensile and shear microcracks) on the mesoscopic scale and the macroscopic mechanical behavior (the strength, and failure patterns) observed in laboratory experiments. The subcritical parameters of the model were calibrated to match the time-dependent damage deformation behavior observed in laboratory experiments. The timedependent numerical results replicated the typical deceleratingaccelerating axial strain behavior seen in laboratory experiments. The crack propagation pattern in the simulation indicated that tension cracks were dominant. The results of numerical simulation showed that the timeto-failure during brittle creep decreased with the increase of the stress level, while the initial strain value, initial damage value, and minimum creep strain rate increased, as observed previously in the laboratory. We conclude therefore that the presented model supports a rich set of grainscale discontinuities that can be related to microstructural features and provides a deeper understanding of the evolution of time-dependent damage on the mesoscale. 


\title{
Mesoscopic time-dependent behavior of rocks based on three-dimensional discrete element grain-based model
}

\author{
Teng-Fei Fu ${ }^{\mathrm{a}, \mathrm{b}}$, Tao Xu ${ }^{\mathrm{a} \mathrm{b}^{*}}$, Michael J. Heap ${ }^{\mathrm{c}}$, Philip G. Meredith ${ }^{\mathrm{d}}$, Thomas M. Mitchell ${ }^{\mathrm{d}}$
}

${ }^{a}$ Key Laboratory of Ministry of Education on Safe Mining of Deep Metal Mines, Northeastern University, Shenyang, Liaoning 110819, China

${ }^{\mathrm{b}}$ Center for Rock Instability and Seismicity Research, Northeastern University, Shenyang, 110819, China

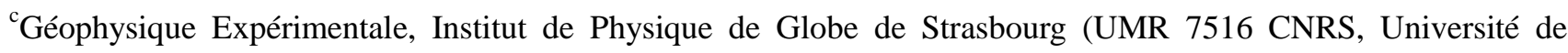
Strasbourg/EOST), 5 rue René Descartes, 67084 Strasbourg cedex, France

${ }^{\mathrm{d}}$ Rock \& Ice Physics Laboratory, Department of Earth Sciences, University College London, Gower Street, London WC1E6BT, UK

*Corresponding author: xutao@mail.neu.edu.cn

\begin{abstract}
A three-dimensional discrete element grain-based stress corrosion model incorporating the theories of subcritical crack growth and chemical reaction rate was built to explore the time-dependent behavior of damage evolution and fracture patterns of brittle rocks on a mesoscopic scale. The model was first validated and the model accurately captured the evolution of damage (tensile and shear microcracks) on the mesoscopic scale and the macroscopic mechanical behavior (the strength, and failure patterns) observed in laboratory experiments. The subcritical parameters of the model were calibrated to match the time-dependent damage deformation behavior observed in laboratory experiments. The time-dependent numerical results replicated the typical decelerating-accelerating axial strain behavior seen in laboratory experiments. The crack propagation pattern in the simulation indicated that tension cracks were dominant. The results of numerical simulation showed that the time-to-failure during brittle creep decreased with the increase of the stress level, while the initial strain value, initial damage value, and minimum creep strain rate increased, as observed previously in the laboratory. We conclude therefore that the
\end{abstract}


presented model supports a rich set of grain-scale discontinuities that can be related to microstructural features and provides a deeper understanding of the evolution of time-dependent damage on the mesoscale.

Keywords: stress corrosion; Voronoi polyhedral; discrete element method; time-dependent behavior; brittle rocks

\section{Introduction}

The majority of rocks forming the Earth's crust exhibit complex mechanical behavior associated with their internal microstructure. Hence, rock microstructure is one of the key factors controlling the progressive failure of rocks, which involves the closure, initiation, interaction and coalescence of microcracks, eventually resulting in macroscopic failure of the rock under external loading [1-3]. However, laboratory experiments have demonstrated that the deformation of rock materials (e.g., sandstone, basalt, granite) can progress with time under constant stress that is below their short-term failure strength. Rock held under a constant stress can eventually fail, with the time-to-failure depending inversely on the magnitude of the differential stress, amongst other factors such as temperature and the nature of any pore fluid that is present [1, 4-8]; a phenomenon known as static fatigue in the engineering literature and brittle creep in the geoscience literature. This time-dependent deformation is often explained in terms of time-dependent subcritical crack growth [9-12]. Time-dependent damage and failure of rock has the potential to significantly impact on long-term stability and safety considerations of geotechnical structures such as mines [13], underground tunnels and wellbores [14, 15], nuclear waste repositories [16], and rock slopes [17].

The main underlying physical mechanisms of subcritical crack growth under upper crustal conditions include stress corrosion, dissolution, diffusion, ion exchange, and microplasticity [18]. Geological fluids (commonly water or aqueous solutions) are ubiquitous in the Earth's brittle upper crust, and all of the physical mechanisms responsible for subcritical crack growth are likely to be influenced by the chemical effects of pore water [18-22]. Atkinson [18] postulated that stress corrosion would likely be the main mechanism of subcritical crack growth 
under shallow crustal conditions (upper $20 \mathrm{~km}$ ). Stress corrosion is driven by reactions that occur preferentially between a chemically activated geological fluid (commonly water) and the strained bonds at crack tips, such as the hydrolysis of silicon-oxygen bonds in a quartz-water system [6, 7, 19, 23-25]. The strained crack tip bonds result in a weakened (activated) state that can be broken at lower stresses than unaffected bonds.

Based on stress corrosion theory, a number of numerical modelling approaches have been proposed to analyze time-dependent damage of brittle rocks. Amitrano and Helmstetter [26], for example, proposed a numerical model based on static fatigue laws to simulate brittle creep using a two-dimensional finite element method with the assumption of plane strain. Each element of the finite element model adopted an empirical relation between time-to-failure and applied stress. Konietzky and Heftenberger [27] proposed numerical model in FLAC2D (2D Fast Lagrangian Analysis of Continua) to simulate subcritical crack growth and perform time-to-failure prediction of a rock structure under constant loading using a linear elastic fracture mechanical approach. As a further development of the model proposed by Li and Konietzky [28, 29]. Li and Konietzky [29] studied time-dependent crack growth by considering stochastic distributions for the initial length and orientation of cracks and different crack propagation schemes in brittle rock. Potyondy [30] adopted reaction rate theory into the bonding model of PFC (Particle Flow Code) to simulate the stress-dependent corrosion reactions that occur at each parallel bond in silicate rock analogues. The stress corrosion process is implemented by decreasing parallel-bond diameter at a uniform rate that is proportional to the crack velocity proposed by Charles [24]. Kemeny [31] developed a fracture mechanics model in UDEC (Universal Distinct Element Code) to simulate the time-dependent degradation of rock joint cohesion of rock bridges along discontinuities. Chen and Konietzky [32, 33] developed a grain-based numerical model in UDEC to simulate time-dependent behavior in terms of damage evolution, successfully describing the brittle creep curve (strain as a function of time). The modeling of Chen and Konietzky [32, 33] considers randomly distributed initial microcracks, different mineral components, and different grain sizes. 
The main objective of this study was to further advance our understanding of the time-dependent damage evolution of brittle rock at the mesoscale. In this paper, the mesoscale is considered to be the length scale (the mineral grain scale) between the macroscale (phenomenological) and the microscale (atomic or molecular). For this purpose, we used the three-dimensional discrete element grain-based model (3DEC-GBM) to represent rock by a dense packing of 3D Voronoi grains (convex polyhedra intersecting along flat faces, straight edges and vertices, respectively [34]) of non-uniform size and shape that are bonded together at grain contacts. A calibration procedure to determine the grain scale parameters (for grains and grain-to-grain contacts) for the model was conducted using the macroscopic response of rock deformed in laboratory experiments. Complete stress-strain curves and failure pattern analysis were then modeled to validate the model against laboratory observations. Following this validation, the time-dependent behavior of brittle rock was introduced into the 3DEC-GBM using stress corrosion theory. Two simple models were built to analyze visually subcritical crack growth at the contact between grains. Finally, we performed a set of uniaxial compressive creep simulations under different constant stresses to study time-dependent damage evolution of the studied sandstone.

\section{Theory of subcritical crack growth}

Stress corrosion, a weakening reaction of a bond structure in rock materials by a chemical reaction, is considered to be one of the key factors driving the time-dependent behavior of rocks in the upper crust. The well-known Charles power law is the most commonly used equation to describe subcritical crack growth $[18,19$, $23,24,35-37]$. Charles [23, 24] investigated static fatigue of a simple soda-lime glass in relation to the sensitivity of this glass to water vapor corrosion under tensile loading. The formula that describes the relation between subcritical crack growth velocity and stress intensity factor in terms of chemically assisted stress corrosion processes is given by

$$
v=v_{0} \exp (-\Delta H / R T) K_{I}^{n}
$$


where $v$ is the crack velocity, $v_{0}$ is pre-exponential factors, $\Delta H$ is an activation enthalpy, $R$ is the universal gas constant, $T$ is the absolute temperature, $n$ is a material constant known as the stress corrosion index, and $K_{I}$ is the stress intensity factor. The corrosion process was found to be strongly dependent on stress at the tip of the crack.

Wiederhorn $[38,39]$ further hypothesized that static fatigue in glass is the result of a stress-induced chemical process between the ambient environment and the glass, based on chemical reaction rate theory. The crack velocity is proportional to the rate of chemical reaction at the crack tip. A quantitative rate equation to describe the crack velocity is given by [30]

$$
v=v_{0} \exp \left(\frac{v^{+} \sigma-E^{+}+v_{M} \gamma / \rho}{R T}\right)
$$

where $v^{+}$is the activation volume, $\sigma$ is the crack-tip tensile stress, $E^{+}$is the stress-free activation energy, $v_{M}$ is the molar volume of the glass, $\gamma$ is the interfacial surface energy between the glass and the reaction products and $\rho$ is the radius of curvature of the crack tip. This equation was not formulated in terms of fracture mechanics parameters, such as stress intensity factor $K_{I}$.

Michalske and Freiman [9], Freiman [10] developed a chemical model on a molecular scale for the stress-induced interaction of the environment with mechanically strained bonds at the tip of a crack in the silica-water system, and explained that the stress corrosion process in polycrystalline ceramics is dominated by grain boundary chemistry and structure. They also assumed that the crack velocity is directly proportional to the chemical reaction rate. Martin [35], Scholz [36], Atkinson and Meredith [11], Atkinson [18], Atkinson [19] reported on static fatigue in various rocks and rock-forming minerals (e.g., quartz, calcite, basalt, granite). They demonstrated that the static fatigue of rocks is dependent upon stress, temperature, and moisture (similar to the time-dependent crack growth in glasses or ceramics). Therefore, Eq. (2) could be extended to describe subcritical crack growth of minerals and rocks. 


\section{The numerical model}

\subsection{The three-dimensional discrete element grain-based model (3DEC-GBM)}

In this study, a three-dimensional Voronoi tessellation model was built using Neper (a software package for polycrystal generation and meshing), which was then imported directly into 3DEC (3 Dimensional Distinct Element Code)[34, 40, 41]. Voronoi tessellation randomly generates polyhedral grains with variable sizes and shapes, which is representative of random polyhedral grains or the polycrystalline meso-structures of natural rocks (see Fig. 1). We generated numerical cylindrical specimens with a diameter of $50 \mathrm{~mm}$ and a height of $100 \mathrm{~mm}$ (the same dimensions as for the laboratory experiments described later in this paper) in order to deform them numerically. Each specimen consisted of 5,300 Voronoi polyhedron grains, as shown in Fig. 2(a). All grains in the Neper are convex polyhedrons. Equivalent diameters (i.e. diameter of the sphere of equivalent volume) of the grains in the model follow a log-normal distribution, in which the logarithmic mean and logarithmic standard deviation are 1 and 0.35 , respectively. The sphericity (i.e. the ratio of the surface area of the sphere of equivalent volume to the surface area of the grain [42] ) of the grains in the model also follows a log-normal distribution, in which the logarithmic mean and logarithmic standard deviation are 0.145 and 0.03 , respectively. It should be noted that a numerical model that can exactly reproduce the actual grain structure of a rock is impractical due to a result of computing limitations; therefore, our model incorporates a minimum grain size set at 13 times the actual grain in an effort to reflect closely the model response [34]. The measurement system of the numerical model is shown in Fig. 2(b) (the same approach used in [34]). The axial strain was calculated by averaging the z-direction displacement (along the axis of the sample) between two pairs of grid points. These pairs of grid points were located $10 \mathrm{~mm}$ from the top and bottom ends of the model, respectively (Fig. 2(b)). Lateral strain was calculated by averaging the horizontal displacement of three pairs of grid points located in the middle section of the specimen (Fig. 2(b)). The axial stress was calculated by monitoring the stress in the central region of the model (the red 
region indicated in Fig. 2(b)).

Fig. 1

Fig. 2

Both grains and grain contacts in the numerical model control the macroscopic behavior of the specimen [43,

44]. In this study, the deformable grains were assigned linear elastic constitutive relations, and the grain contacts were assigned two contact criteria: derived from Rankine's maximum tensile stress theory and Mohr-Coulomb shear failure theory. Contacts between grains were automatically divided into several triangular sub-contacts after the entire grain was zoned. The transfer of force between grains was achieved through these sub-contacts. Once the stress at the sub-contact reached the strength threshold, the sub-contact either slid or opened (Fig. 3).

Fig. 3

As the rock is deformed, microcracks form and are accompanied by the release of strain energy in the form of elastic waves known as acoustic emissions (AEs) [45]. Laboratory experiments have shown that the number and amplitude of AE activity increases as a rock approaches macroscopic failure [46]. Tang [47] related the number of failed elements, a proxy for AE, during a Rock Failure Process Analysis (RFPA) simulation to the damage accrued by the deforming numerical sample. Indeed, both experiments and modeling have shown that the output of AE is a reliable metric to monitor the evolution of damage in rock samples. In three-dimensional discrete element grain-based models, the damage, a metric to quantitatively describe the failure process of a rock sample, is represented explicitly as broken sub-contacts (which will be referred to as microcracks). Here, damage (D) is defined as the ratio of the accumulated number of sub-contact failures to the number of total sub-contact failures in the model:

$$
D=\frac{\sum_{i=1}^{\mathrm{m}} n_{i}}{\sum_{i=1}^{\mathrm{M}} n_{i}}
$$

where $m$ is the current time step, $n_{i}$ is the number of sub-contact failures in the ith time step, and $M$ is the total 
number of time steps (with very few cracks being generated after the $M t h$ time step).

\subsection{Formulation of the time-dependent model}

Stress corrosion theory was introduced into the three-dimensional discrete element grain-based model (3DEC-GBM) to mimic time-dependent weakening processes in rock at the mesoscale. Synthetic specimens, analogous to granular rocks, are constructed in 3DEC-GBM through a dense packing of non-uniform-sized Voronoi grains bonded together at their contacts. We assume that stress corrosion reactions only occur at sub-contacts between grains and do not affect the grains themselves. Therefore, each sub-contact is a potential reaction site, and microcracks only propagate along the grain boundaries. The mesoscopic mechanical properties of the sub-contacts, which involve the tensile strength and cohesion in this study, are weakened at a uniform rate that is proportional to the chemical reaction rate, hereinafter called the degradation rate (Fig. 4). The friction angle of a contact is largely related to its roughness and barely influences the reduction in contact strength $[48,49]$. Therefore, we assume that the friction angle cannot account for the decrease in mechanical strength with time [49]

Fig. 4

When time-dependent behavior of rock at constant temperature and humidity is studied, the formula that describes the degradation rate $\left(v_{D}\right)$ of mesoscopic mechanical properties of the sub-contacts is given by:

$$
v_{D}=\left\{\begin{array}{cl}
0 & \bar{\sigma}<\sigma_{0} \\
B_{1} e^{B_{2} \bar{\sigma}}, & \sigma_{0} \leq \bar{\sigma}<\sigma_{c} \\
\infty & \bar{\sigma}>\sigma_{c}
\end{array}\right.
$$

where $B_{1}=A v_{0} e^{\left(-\left(E^{+}+v_{M} \gamma / \rho\right) / R T\right)}$ and $B_{2}=v^{+} / R T, \sigma_{0}$ is the threshold stress (or so-called activation stress) below which stress corrosion reactions cannot occur (approximately equal to $0.4^{*} \sigma_{c}[30]$ ), $\sigma_{c}$ is the peak strength, $\bar{\sigma}$ is the reaction-site stress at the sub-contact, and $\mathrm{A}$ is the constant of proportionality between the chemical reaction rate and the degradation rate. Once the normal stress or shear stress at the sub-contact exceeded the tensile strength or shear strength at the sub-contact, respectively, the sub-contacts failed and formed microcracks. 
The proposed time-dependent model can simulate microcrack nucleation, growth and eventual interaction at the grain scale, but the stress corrosion process at the sub-contacts is not described by a stress-intensity factor. As Potyondy [30] mentioned when describing their parallel-bonded stress corrosion (PSC) model, linear elastic elastic fracture mechanics (LEFM) conditions only apply to microcracks that are long relative to the grain size, and characterizes the stress field at the crack tip when a sufficient number of these microcracks coalesce into a macroscopic fracture [30]. Only when the microcracks along grains boundaries coalesce and localize into a macroscopic fracture, whose length is large relative to the grain size, in 3DEC-GBM, can the conditions at the macrocrack tip be characterized by the stress-intensity factor. This suggests that the proposed model supports a richer set of grain-scale microcracks, and it encompasses the physical behavior mechanisms of the LEFM models.

In addition, Atkinson [19], Das and Scholz [21] assumed that, although stress corrosion has only been observed for mode I (tensile) crack growth, there appears to be no physicochemical reason why the stress corrosion process should depend on mode. The form of the stress corrosion theory therefore does not depend on crack tip displacement mode, and this implies that stress corrosion influences crack growth in all three crack tip displacement modes. Therefore, it is assumed that the form of equations describing stress corrosion under shear loading should be the same as that for crack propagation under tensile loading in Eq. (4), even if the values of the parameters in these equations are different. We study the reaction-site stress, which would incorporate tensile stress, shear stress or mixed stress acting on the sub-contact, to simulate subcritical crack growth in 3DEC-GBM.

When tensile loading is applied to the sub-contact, the degradation rate is given by:

$$
v_{D}=\left\{\begin{array}{cl}
0 & \bar{\sigma}<\sigma_{0} \\
B_{l t} e^{B_{2 t} \bar{\sigma}}, & \sigma_{0} \leq \bar{\sigma}<\sigma_{c} \\
\infty & \bar{\sigma}>\sigma_{c}
\end{array}\right.
$$

where $\bar{\sigma}$ is the microtension at the sub-contact. $B_{1 t}$ and $B_{2 t}$ are material constants that vary with temperature and chemical environment. 
When shear loading is applied to the sub-contact, the degradation rate is given by

$$
v_{D}=\left\{\begin{array}{cl}
0 & \bar{\tau}<\sigma_{0} \\
B_{1 s} e^{B_{2 s} \bar{\tau}} & \sigma_{0} \leq \bar{\tau}<\sigma_{c} \\
\infty & \bar{\tau}>\sigma_{c}
\end{array}\right.
$$

where $\bar{\tau}$ is the microshear at the sub-contact, $B_{l s}$ and $B_{2 s}$ are material constants that vary with temperature and chemical environment.

When mixed tensile-shear loading is applied to the sub-contact, the degradation rate is obtained by utilizing the principle of superposition:

$$
v_{D}=\left\{\begin{array}{cl}
0 & \bar{\sigma}<\sigma_{0} \text { or } \bar{\tau}<\sigma_{0} \\
B_{l t} e^{B_{2 t} \bar{\sigma}}+B_{l s} e^{B_{2 s} \bar{\tau}} & \sigma_{0} \leq \bar{\sigma}<\sigma_{c} \text { or } \sigma_{0} \leq \bar{\tau}<\sigma_{c} \\
\infty & \bar{\sigma}>\sigma_{c} \text { or } \bar{\tau}>\sigma_{c}
\end{array}\right.
$$

where $\bar{\sigma}$ and $\bar{\tau}$ are the microtension and microshear at the sub-contact, respectively.

When mixed compressive-shear loading is applied to the sub-contact, frictional forces are generated along the sub-contact. The shear stress $\bar{\tau}$ at the sub-contact can be substituted by the effective shear stress above friction, $\bar{\tau}-\sigma_{n} \tan \varphi$, and the degradation rate is then given by:

$$
v_{D}=\left\{\begin{array}{cl}
0 & \bar{\tau}-\sigma_{n} \tan \varphi<\sigma_{0} \\
B_{I s} e^{B_{2 s}\left(\bar{\tau}-\sigma_{n} \tan \varphi\right)} & \sigma_{0} \leq \bar{\tau}-\sigma_{n} \tan \varphi<\sigma_{c} \\
\infty & \bar{\tau}-\sigma_{n} \tan \varphi>\sigma_{c}
\end{array}\right.
$$

where $\bar{\tau}$ and $\sigma_{\mathrm{n}}$ are the microshear and normal stress at the sub-contact, respectively.

For time-dependent phenomena such as static fatigue, 3DEC includes two separate accumulated times: the problem time and the timestep. The problem time represents real time, and the time step is an artificial quantity, used as a means of stepping to a steady-state condition [50]. For a stress-corrosion simulation, the stress-corrosion time step, $\Delta \mathrm{t}$, is taken as real time, and can be automatically adjusted via a self-adaptive procedure. The initial stress-corrosion time step is equal to $1 \mathrm{~s}$. When the maximum unbalanced force in the model exceeds some threshold, the stress-corrosion time step, $\Delta \mathrm{t}$, can be decreased by a ratio equal to 0.9 . The specified minimum time 
step is $1 \times 10^{-2} \mathrm{~s}$. When the maximum unbalanced force goes below some threshold, the stress-corrosion time step, $\Delta \mathrm{t}$, can be increased by a ratio equal to 1.1 . The specified maximum time step is $1 \times 10^{4} \mathrm{~s}$. The threshold mentioned above is defined as the ratio of the maximum unbalanced force to the average grid point force of the model [50] and can be calculated as follows:

$$
\alpha=\frac{F_{u n b}}{\left(\sum_{\mathrm{i}=1}^{N} F_{g p \mathrm{i}}\right) / N}
$$

where $\alpha$ is the threshold, $F_{\text {unb }}$ is the maximum unbalanced force in the model, $N$ is the total number of grid points in the model, $F_{g p i}$ is the grid point force of the $i t h$ grid point in the model.

\section{Modeling of time-dependent deformation of rock}

In this study, the time-dependent damage evolution of Yunnan sandstone (from the Yunnan province of China) at the mesoscale was studied using a combination of numerical modeling and laboratory testing. Cylindrical samples (50 in diameter and $100 \mathrm{~mm}$ in length) were prepared from a single block of Yunnan sandstone. Yunnan sandstone is a feldspathic sandstone consisting of quartz (60\%), feldspar (19\%), calcite (8\%), and cement (13\%), and it has a grain size of approximately 100-200 $\mu \mathrm{m}$. Yunnan sandstone was selected because its microstructure (polygonal grains) is very similar to that of the numerical samples prepared using the Voronoi polyhedra grains (Fig. 1). The macroscopic mechanical properties of Yunnan sandstone are summarized in Table 1. The macroscopic mechanical properties of Yunnan sandstone are summarized in Table 1. The mechanical properties of specimen SZ-08 and SZ-16 were used to determine the macro response of Yunnan sandstone.

Table 1

\subsection{Parameter calibration}

For continuum approaches (e.g., finite element and finite difference method), material properties can be directly obtained through laboratory testing. However, for discontinuum approaches, especially the DEM, the material parameters of both the grains and grain contacts control the macroscopic mechanical behavior of the rock. 
These parameters cannot be directly obtained from laboratory testing, but are related to the macroscopic mechanical response of rock during classical laboratory tests (e.g., uniaxial compression testing and Brazilian disc tensile testing). For DEM, a "trial-and-error" method is often used [44, 51], in which numerical modeling is performed and the input parameters are varied until the mechanical behavior, strength, and failure patterns of the numerical simulation closely match the data and observations from laboratory experiments. Numerous publications have shown how the mesoscopic material parameters of rocks can be calibrated for use in modeling [30, 34, 40, 43, 44].

In this study, only one type of grain and one type of contact are considered in the parametric study, which means that the effects of mineral heterogeneity are explicitly not considered. The deformation and strength parameters for the grains are chosen based on the mean values of Yunnan sandstone and therefore the elastic constants (Young's modulus and Poisson's ratio) of the grains are considered as real values (Table 2). The calibrated meso-mechanical parameters for Yunnan sandstone are listed in Table 2. The uniaxial compression results obtained from the laboratory testing and numerical simulations on Yunnan sandstone are then compared in Figs. 5 and 6. It was found that the numerical simulation can accurately reproduce the mechanical behavior (e.g., the elastic modulus) and strength of the laboratory experiment (Fig. 5). The simulated peak stress of $52 \mathrm{MPa}$ was very close to the experimentally measured uniaxial compressive strength of $52.1 \mathrm{MPa}$, and the simulated and experimental Young's moduli were both $12 \mathrm{GPa}$. We observed that a macroscopic shear fracture zone in the numerical sample, accompanied by several minor ancillary fractures (Fig. 6a), agrees well with the macroscopic failure of the laboratory experiment (Fig. 6b).

Table 2

Fig. 5

Fig. 6

We highlight that the shape of the experimental stress-strain curve in Figure 5 was initially non-linear 
(concave) up to an axial strain of $0.27 \%$. This type of deformation is often observed in laboratory experiments and is commonly attributed to both the settlement of elements of the loading train and closure of pre-existing defects, such as microcracks. These secondary processes are not taken into consideration in the numerical model, hence the model stress-strain curve does not contain this initial non-linear portion. However, if we remove this initial concave portion of the experimental stress-strain curve, we find that the numerical and experimental stress-strain curves are essentially superimposed upon each other (the solid blue and dashed pink curves, respectively, in Fig. 5). Furthermore, we find that the peak stress and the Young's modulus (i.e. the slope of the stress-strain curve in the elastic region) from the numerical simulation were essentially the same as for the experiment (Fig. 5). Therefore, although the model is unable to capture the initial concave portion of the stress-strain curve associated with the closure of microcracks and apparatus settlement, it is able to accurately reproduce the mechanical behavior and strength of the laboratory experiment (Fig. 5).

\subsection{Stress corrosion process}

Two simple numerical models were built to analyze microcrack growth at the contacts between grains, as shown in Fig. 7. Two adjacent Voronoi polyhedral grains were randomly selected from the 3DEC-GBM and represented in simplified form as two cube grains ( $2.5 \mathrm{~mm}$ edge length). The stress corrosion mechanism was then implemented in the simple numerical model, under conditions where stress corrosion reactions can only occur within the contact area between the two cubic grains. The contact between the grains was automatically divided into several triangular sub-contacts after the entire grain was zoned. The degradation of sub-contact strength with time is ruled by Eq. (4). The stress corrosion takes place with extremely low speed. Once the stress at any of the sub-contacts exceeded the sub-contact strength, that sub-contact was deemed to have failed and transformed into a microcrack. The microcrack subsequently propagates subcritically across the whole contact. The calibrated mechanical parameters listed in Table 2 were used as the input parameters for these two numerical models. 
Fig. 7

The subcritical parameters in Eq. (4) were analyzed based on a tensile test and a shear test in the model. Fig. 8 shows the influence of the subcritical parameters on time-to-failure of the model. When the subcritical parameter $\mathrm{B}_{2 \mathrm{t}}$ was equal to $3.5 \times 10^{-9}$, the time-to-failure nonlinearly decreased as a function of increasing $\mathrm{B}_{1 \mathrm{t}}$ under a constant tensile load (Fig. 8a, left). Time-to-failure also decreased as a function of increasing tensile load (Fig. 8a, left). Similarly, when the subcritical parameter $\mathrm{B}_{1 \mathrm{t}}$ was equal to $4.3 \times 10^{-9}$, the time-to-failure decreased as a function of increasing $\mathrm{B}_{2 \mathrm{t}}$ under constant tensile load (Fig. 8a, right). Time-to-failure also decreased as a function of increasing tensile load (Fig. 8a, right). A similar pattern is seen for the model under a shear load, as shown in Fig. 8b.

Fig. 8

During simulations under tensile loading, the short-term failure strength of the model with a pre-existing crack was 3.6 MPa. The subcritical parameters were: $\mathrm{B}_{1 \mathrm{t}}=4.3 \times 10^{-4}$ and $\mathrm{B}_{2 \mathrm{t}}=3.5 \times 10^{-9}$, and a threshold stress $\bar{\sigma}$ (below which stress corrosion ceases ) was 1.4 MPa. Fig. 9(a) shows the modeled distribution of z-direction stress (tensile stress) and microcrack development as a function of time under a constant tensile stress of 2.2 MPa. A stress concentration was observed around the pre-existing crack or the newly created microcrack tips. It can be concluded that the greater tensile load, the faster degradation rate of the sub-contact at the microcrack tip. The sub-contacts would consequently fail under a lower tensile stress and form a microcrack. The microcrack gradually propagated over time, and the time-to-failure was $1.36 \times 10^{4} \mathrm{~s}$. When the microcrack passed through the contact between grains, the model failed and the stresses were released. During simulations under shear loading, the short-term failure strength of the model without a pre-existing crack was 5.7 MPa. The subcritical parameters were $\mathrm{B}_{1 \mathrm{~s}}=4.3 \times 10^{-4}$ and $\mathrm{B}_{2 \mathrm{~s}}=3.5 \times 10^{-9}$, and the threshold stress $\bar{\sigma}$ was $2.3 \mathrm{MPa}$. Fig. 9(b) shows the distribution of $\mathrm{x}$-direction stress (shear stress) in the model and microcrack development with time under a constant shear stress of 3.6 MPa. Similarly to the tensile case, stress concentrations were observed around the pre-existing crack or the 
newly created microcrack tip. Similarly, the sub-contacts failed gradually over time, and the microcrack propagated subcritically along the grain contact.

Fig. 9

\subsection{Uniaxial compressive creep tests}

In order to simulate the time-dependent evolution of crack damage within our numerical cylindrical specimens (100 $\mathrm{mm}$ in length and $50 \mathrm{~mm}$ in diameter) under different stress levels, a series of numerical simulations using the stress corrosion theory were first conducted to find the appropriate subcritical crack growth parameters. The calibrated subcritical crack growth parameters were $\mathrm{B}_{1 \mathrm{t}}=\mathrm{B}_{1 \mathrm{~s}}=1.8 \times 10^{-3}$ and $\mathrm{B}_{2 \mathrm{t}}=\mathrm{B}_{2 \mathrm{~s}}=3.5 \times 10^{-8}$, respectively. A representative simulated creep curve (under 41.6 MPa constant uniaxial stress) is shown in Fig. 10, where the strain, the evolution of damage, and the axial strain rate are plotted as functions of time.

For comparison, a brittle creep experiment was run on a real rock sample. The experimental specimen was first loaded uniaxially at a constant displacement rate to a pre-chosen constant stress level. The specimen was then allowed to deform over time under this constant stress (maintained by a servo-control system) until failure occurred. Fig. 11 shows the creep curves (i.e. axial strain as a function of time) for both the laboratory and simulated creep tests on the studied sandstone (the simulation is the same as shown in Fig. 10). Fig. 11 also shows the modeled cumulative number of tensile and shear microcracks as functions of time.

The simulation results are qualitatively similar both to the experimental results of Figure 10 and to previously published experimental creep curves [6, 52]; an initial phase of decelerating strain followed by a phase of accelerating strain (Figs. 10 and 11), although we note that the decelerating phase is more pronounced in the experimental data (Fig. 11). During the initial constant stress phase of the simulation, significant instantaneous deformation occurred in the sample. The axial strain and damage value of the specimen reached $3.57 \times 10^{-3}$ and 0.17, respectively (Fig. 10a). Only a small number of microcracks was generated during this phase (Fig. 11). The 
axial strain rate, the lateral strain and the volumetric strain all decreased during the phase (so called "primary" creep phase), but the axial strain increased (Figs. 10). During "secondary" creep phase, the formation of microcracks (dominantly tensile microcracks) slowly increased (Fig. 11). The minimum axial strain rate, a metric often used to characterize brittle creep in experiments, was $2.11 \times 10^{-10} \mathrm{~s}^{-1}$ (Figs. 10). After an extended period, the axial strain rate noticeably increased (the so-called "tertiary" creep phase). The axial strain at this point was approximately $3.64 \times 10^{-3}$ (see inset in Fig. 10(a)). The formation of microcracks increased significantly during this final stage (Fig. 11). The strain value and damage value also accelerated suddenly, eventually resulting in a macroscopic shear fracture (i.e. sample failure) (Fig. 10). The time-to-failure of the sample was approximately $3.14 \times 10^{5} \mathrm{~s}$. The volume strain-time curve shows that the sample was dilating throughout brittle creep (Fig. 10(b)). The rate of damage exhibits the same general trend as the creep curve (axial strain as a function of time); the rate of damage first decelerated before eventually accelerating as sample failure was approached. Overall, the numerical and experimental creep curves show very similar trends, and are approximately superimposed beyond the very first part of the deformation (solid block curve and dashed red curve, respectively, in Fig. 11), demonstrating that the proposed model can accurately reproduce the time-dependent mechanical behavior of the laboratory experiment.

Fig. 10

Fig. 11

Now that we have shown that the model can accurately capture the mechanical behavior of a brittle creep experiment, we can use the model to further explore time-dependent brittle deformation in rocks under different loading conditions. Fig. 12 shows five more simulated uniaxial compressive creep curves (axial strain, lateral strain, and damage as a function of time) for the studied sandstone performed at constant stresses of 70, 80, 85, 90, and 95\% of the short-term strength, $\sigma_{\mathrm{c}}$, corresponding to $36.4,41.6,44.2,46.8$, and $49.4 \mathrm{MPa}$, respectively. Note that the sample held at $70 \%$ of the short-term strength did not fail even after $100 \mathrm{~h}$. As the constant stress was increased 
from $80 \%$ to $95 \%$ of $\sigma_{\mathrm{c}}$ (i.e. from $41.6 \mathrm{MPa}$ to $49.4 \mathrm{MPa}$ ), we observed an approximately 20 -fold decrease in time-to-failure of the numerical specimen from $3.14 \times 10^{5}$ to $1.70 \times 10^{4} \mathrm{~s}$ (Fig. 12; Table 3). We also observed that small increases in the applied creep stress resulted in very large increases in the minimum creep strain rate (Fig. 13;

Table 3), and associated large decreases in the times-to-failure (Table 3), as previously observed in laboratory experiments (see Brantut et al. 2013 and references therein). For example, the sample held at $85 \%$ of the short-term strength failed after approximately $1.15 \times 10^{5} \mathrm{~s}$ and its minimum creep strain rate was $3.75 \times 10^{-9} \mathrm{~s}^{-1}$. Increasing the creep stress by only a small amount to $90 \%$ of the short-term strength resulted in a decrease in the time-to-failure by about a factor of 4 to about $2.92 \times 10^{4} \mathrm{~s}$, and an increase in axial strain rate by about a factor of 6 to $2.42 \times 10^{-8} \mathrm{~s}^{-1}$ (Fig. 12; Table 3). The minimum creep strain rate for these five experiments increased from $3.37 \times 10^{-11} \mathrm{~s}^{-1}$ to $5.95 \times 10^{-8} \mathrm{~s}^{-1}$, as the constant stress was increased from 36.4 to $49.4 \mathrm{MPa}$ (Fig. 13). We observed similar trends in the evolution of both axial and lateral strain rates with increasing axial (creep) stress (Fig. 13). For a given axial stress, the lateral strain rate was higher than the axial strain rate (Fig. 13). Fig. 12(c) shows plots of the cumulative damage as a function of time for all of the creep simulations shown in Figs. 12 and 13. We note that the evolution of damage is qualitatively similar to the evolution of axial strain with time, shown in Fig. 12(a).

Fig. 12

Fig. 13

\section{Discussion: model limitations and further work}

The three-dimensional polycrystalline discrete element model used herein has proved to be a useful tool for modeling synthetic specimens analogous to granular rocks (e.g., sandstone). This type of modeling creates new possibilities to allow for a realistic simulation of time-dependent rock mechanical behavior and strength. However, it is not possible to exactly reproduce the grain scale structure of rock due to the limitations of computer performance. Hence, a degree of simplification is always required. Fabjan et al. [53] demonstrated that the 
influence of the polygon size resolution on the rock strength can be eliminated by having more than ten polygons along the diameter of the specimen's cross section, which is the case for the simulations reported here (Fig. 2). Furthermore, a specimen consisting of 5,300 Voronoi polyhedron grains, as used in this study, agrees well with the discretization of the numerical specimens used in other studies[34].

When the local stresses exceed the local strength within rock under external loading, opening occurs and sub-contacts form microcracks. Based on the location of the microcracks generated during the process of rock failure, they can be divided into three types: intergranular cracks (along mineral grain boundaries), intragranular cracks (within the mineral grains) and transgranular cracks (cutting across several mineral grains and grain boundaries) [54-56]. Gao and Stead [44, 57] proposed a modified distinct element Voronoi method to simulate the intergranular and intragranular cracking of sandstone in UDEC. They cut each Voronoi block into several triangular blocks by creating several contacts from the center of the grain block to its apex. The contacts between the Voronoi blocks were defined as potential intergranular cracks. Wang and Cai [41] proposed a 3DEC-GBM modeling approach to simulate intergranular cracks and intragranular cracks based on a two-scale Voronoi tessellation scheme in Neper software. In this study, the model simplifies the Voronoi grains as non-breakable and deformable grains. To build on the work presented herein, we consider it necessary also to consider the influence of potential intragranular cracks on unstable cracking in 3DEC-GBM.

Atkinson[12], Charles[23, 24], Wiederhorn and Fuller[58] reported a considerable body of experimental work that studied subcritical crack growth in glasses, ceramics, and geological materials. These experimental results showed that the chemical reaction rate in those materials has been characterized as a function of the applied stress, temperature, and fluid pressure or humidity (see also Brantut et al., 2013). It was assumed that the crack velocity was proportional to the rate of chemical reaction at the crack tip during subcritical crack growth driven by stress corrosion. When the temperature and humidity were increased, the crack growth rate was also increased due to the 
increased activity of environmental water. In this paper, the stress corrosion process is incorporated into a three-dimensional grain-based discrete element model (3DEC-GBM) to simulate time-dependent deformation and damage under constant temperature and humidity. Future research will focus on the effects of varying temperature and humidity on time-dependent deformation using the model presented herein.

\section{Conclusion}

In this study, we employed a three-dimensional discrete element grain-based model (3DEC-GBM) to characterize the time-dependent progressive damage evolution of the studied sandstone at the mesoscopic scale. The 3DEC-GBM was validated against laboratory uniaxial compression experiments. We found that the model could accurately capture the mechanical behavior, strength, and failure patterns obtained in laboratory experiments (here demonstrated for the Yunnan sandstone). Based on this validation, and the stress-dependent corrosion reaction theory, a grain-based corrosion reaction model was developed to capture the time-dependent degradation of rock at the mesoscale. As an example, two sample numerical models were analyzed under tensile and shear loading. We observed that sub-contacts between grains failed and formed microcracks over time. Further, a set of uniaxial compressive creep simulations were performed under different constant axial stresses (from 36.4 to $49.4 \mathrm{MPa}$ ). We found that the growth of macrofractures in sandstone samples was dominated by tensile microcracks, and that the damage in the specimen was stress sensitive (i.e. the time-to-failure is shorter under higher constant stress), as also reported in earlier experimental studies. We also found that the final failure pattern and the damage evolution as a function of time were in close agreement with data from laboratory experiments. We conclude that the model presented herein is a powerful tool that can be used to study the time-dependent damage evolution and failure patterns of granular materials at the mesoscale.

\section{Acknowledgments}

The work was jointly supported by National Natural Science Foundation of China (51974062, 41672301, 
51811530312 and 51761135102), National Key Research and Development Program of China (2017YFC1503100),

Fundamental Research Funds for the Central Universities of China (N180101028), a Royal Society International Exchange grant, United Kingdom (IEClNSFC \170625) and a Partenariats Hubert Curien (PHC) Cai Yuanpei grant, France (36605ZB).

\section{References}

[1] Brantut N, Baud P, Heap M, Meredith P. Micromechanics of brittle creep in rocks. Journal of Geophysical Research: Solid Earth. 2012;117(B8).

[2] Ashby MF, Sammis CG. The damage mechanics of brittle solids in compression. Pure and Applied Geophysics. 1990;133(3):489-521.

[3] Sammis CG, Ashby MF. The failure of brittle porous solids under compressive stress states. Acta Metallurgica. 1986;34(3):511-26.

[4] Heap MJ, Baud P, Meredith PG. Influence of temperature on brittle creep in sandstones. Geophysical Research Letters. 2009;36(19).

[5] Brantut N, Heap MJ, Baud P, Meredith PG. Mechanisms of time-dependent deformation in porous limestone. Journal of Geophysical Research: Solid Earth. 2014;119(7):5444-63.

[6] Heap MJ, Baud P, Meredith PG, Bell AF, Main IG. Time-dependent brittle creep in Darley Dale sandstone. Journal of Geophysical Research. 2009;114(B7).

[7] Xu T, Tang C-a, Zhao J, Li L, Heap M. Modelling the time-dependent rheological behaviour of heterogeneous brittle rocks. Geophysical Journal International. 2012;189(3):1781-96.

[8] Xu T, Zhou GL, Heap MJ, Yang SQ, Konietzky H, Baud P. The modeling of time-dependent deformation and fracturing of brittle rocks under varying confining and pore pressures. Rock Mechanics \& Rock Engineering. 2018;51(10):3241-63. 
[9] Michalske TA, Freiman SW. A molecular interpretation of stress corrosion in silica. Nature. 1982;295(5849):511.

[10] Freiman S. Effects of chemical environments on slow crack growth in glasses and ceramics. Journal of Geophysical Research: Solid Earth. 1984;89(B6):4072-6.

[11] Atkinson BK, Meredith PG. The theory of subcritical crack growth with applications to minerals and rocks. Fracture mechanics of rock. 1987;2(111-66.

[12] Atkinson BK. Subcritical crack growth in geological materials. J Geophys Res. 1984;89(B6):4077-114.

[13] Wang J, Li D, Shang X. Creep failure of roof stratum above mined-out area. Rock mechanics and rock engineering. 2012;45(4):533-46.

[14] Schoenball M, Sahara DP, Kohl T. Time-dependent brittle creep as a mechanism for time-delayed wellbore failure. International Journal of Rock Mechanics and Mining Sciences. 2014;70(400-6.

[15] Zhang L, Liu Y, Yang Q. Study on time-dependent behavior and stability assessment of deep-buried tunnels based on internal state variable theory. Tunnelling and Underground Space Technology. 2016;51(164-74.

[16] Martín LB, Rutqvist J, Birkholzer JT. Long-term modeling of the thermal-hydraulic-mechanical response of a generic salt repository for heat-generating nuclear waste. Engineering Geology. 2015;193(198-211.

[17] Xu T, Xu Q, Deng M, Ma T, Yang T, Tang C-a. A numerical analysis of rock creep-induced slide: a case study from Jiweishan Mountain, China. Environmental Earth Sciences. 2014;72(6):2111-28.

[18] Atkinson BK. Subcritical crack growth in geological materials. Journal of Geophysical Research: Solid Earth. 1984;89(B6):4077-114.

[19] Atkinson BK. Subcritical crack propagation in rocks: theory, experimental results and applications. Journal of Structural Geology. 1982;4(1):41-56.

[20] Das S, Scholz CH. Theory of time-dependent rupture in the Earth. Journal of Geophysical Research: Solid Earth. 1981;86(B7):6039-51. 
[21] Das S, Scholz C. Theory of time-dependent rupture in the Earth. Journal of Geophysical Research: Solid Earth. 1981;86(B7):6039-51.

[22] Darot M, Gueguen Y. Slow crack growth in minerals and rocks: Theory and experiments. pure and applied geophysics. 1986;124(4-5):677-92.

[23] Charles R. Static Fatigue of Glass. I. Journal of Applied Physics. 1958;29(11):1549-53.

[24] Charles R. Static fatigue of glass. II. Journal of Applied Physics. 1958;29(11):1554-60.

[25] Michalske TA, Freiman SW. A molecular interpretation of stress corrosion in silica. Nature. 1982;295(5849):511-2.

[26] Amitrano D, Helmstetter A. Brittle creep, damage, and time to failure in rocks. Journal of Geophysical Research: Solid Earth. 2006;111(B11):n/a-n/a.

[27] Konietzky H, Heftenberger A, Feige M. Life-time prediction for rocks under static compressive and tensile loads: a new simulation approach. Acta Geotechnica. 2009;4(1):73-8.

[28] Li X, Konietzky H. Numerical simulation schemes for time-dependent crack growth in hard brittle rock. Acta Geotechnica. 2014:1-19.

[29] Li X, Konietzky H. Time to failure prediction scheme for rocks. Rock Mech Rock Eng. 2014;47(4):1493-503.

[30] Potyondy DO. Simulating stress corrosion with a bonded-particle model for rock. International Journal of Rock Mechanics and Mining Sciences. 2007;44(5):677-91.

[31] Kemeny J. The time-dependent reduction of sliding cohesion due to rock bridges along discontinuities: a fracture mechanics approach. Rock Mech Rock Eng. 2003;36(1):27-38.

[32] Chen W, Konietzky H. Simulation of heterogeneity, creep, damage and lifetime for loaded brittle rocks. Tectonophysics. 2014;633(0):164-75.

[33] Chen W, Konietzky H, Abbas SM. Numerical simulation of time-independent and -dependent fracturing in sandstone. Engineering Geology. 2015;193(118-31. 
[34] Ghazvinian E, Diederichs MS, Quey R. 3D random Voronoi grain-based models for simulation of brittle rock damage and fabric-guided micro-fracturing. Journal of Rock Mechanics and Geotechnical Engineering. 2014;6(6):506-21.

[35] Martin RJ. Time-dependent crack growth in quartz and its application to the creep of rocks. Journal of Geophysical Research. 1972;77(8):1406-19.

[36] Scholz CH. Static fatigue of quartz. Journal of Geophysical Research. 1972;77(11):2104-14.

[37] Martin III RJ, Durham WB. Mechanisms of crack growth in quartz. Journal of Geophysical Research. 1975;80(35):4837-44.

[38] Wiederhorn S. A chemical interpretation of static fatigue. Journal of the American Ceramic Society. $1972 ; 55(2): 81-5$.

[39] Wiederhorn S. Crack growth as an interpretation of static fatigue. J Non-Cryst Solids. 1975;19(0):169-81.

[40] Li XF, Li HB, Zhao J. 3D polycrystalline discrete element method (3PDEM) for simulation of crack initiation and propagation in granular rock. Computers \& Geotechnics. 2017;90(1):96-112.

[41] Wang X, Cai M. Modeling of brittle rock failure considering inter- and intra-grain contact failures. Computers and Geotechnics. 2018;101(224-44.

[42] Quey R, Dawson PR, Barbe F. Large-scale 3D random polycrystals for the finite element method: Generation, meshing and remeshing. Computer Methods in Applied Mechanics and Engineering. 2011;200(17-20):1729-45.

[43] Kazerani T, Zhao J. Micromechanical parameters in bonded particle method for modelling of brittle material failure. International Journal for Numerical \& Analytical Methods in Geomechanics. 2010;34(18):1877-95.

[44] Gao F, Stead D, Elmo D. Numerical simulation of microstructure of brittle rock using a grain-breakable distinct element grain-based model. Computers and Geotechnics. 2016;78(203-17.

[45] Lockner D. The role of acoustic emission in the study of rock fracture. International Journal of Rock Mechanics and 
Mining Sciences \& Geomechanics Abstracts. 1993;30(7):883-99.

[46] Lockner D, Byerlee J, Kuksenko V, Ponomarev A, Sidorin A. Quasi-static fault growth and shear fracture energy in granite. Nature. 1991;350(6313):39-42.

[47] Tang CA. Numerical simulation of progressive rock failure and associated seismicity. International Journal of Rock Mechanics and Mining Sciences. 1997;34(2):249-\&.

[48] Gao F, Kang H. Grain-Based Discrete-Element Modeling Study on the Effects of Cementation on the Mechanical Behavior of Low-Porosity Brittle Rocks. International Journal of Geomechanics. 2017;17(9).

[49] Bahrani N, Kaiser PK, Valley B. Distinct element method simulation of an analogue for a highly interlocked, non-persistently jointed rockmass. International journal of rock mechanics and mining sciences. 2014;71(117-30.

[50] Itasca. 3DEC. Minneapolis, MN, USA: Itasca Consulting Group Inc.2013.

[51] Farahmand K, Vazaios I, Diederichs MS, Vlachopoulos N. Investigating the scale-dependency of the geometrical and mechanical properties of a moderately jointed rock using a synthetic rock mass (SRM) approach. Computers and Geotechnics. 2018;95(162-79.

[52] Brantut N, Heap MJ, Meredith PG, Baud P. Time-dependent cracking and brittle creep in crustal rocks: A review. Journal of Structural Geology. 2013;52(17-43.

[53] Fabjan T, Ivars DM, Vukadin V. Numerical Simulation of Intact Rock Behaviour Via the Continuum and Voronoi Tessellation Models: A Sensitivity Analysis. Acta Geotechnica Slovenica. 2015;12(2):4-23.

[54] Kranz RL. Microcracks in rocks: a review. Tectonophysics. 1983;100(1-3):449-80.

[55] Kranz R. Crack growth and development during creep of Barre granite. International Journal of Rock Mechanics and Mining Sciences \& Geomechanics Abstracts: Elsevier, 1979. p. 23-35.

[56] Lim SS, Martin CD, Åkesson U. In-situ stress and microcracking in granite cores with depth. Engineering geology. $2012 ; 147(1-13$. 
[57] Gao F, Stead D. The application of a modified Voronoi logic to brittle fracture modelling at the laboratory and field scale. International Journal of Rock Mechanics \& Mining Sciences. 2014;68(68):1-14.

[58] Wiederhorn SM, Fuller ER, Thomson R. Micromechanisms of crack growth in ceramics and glasses in corrosive environments. Metal Science Journal. 1980;14(8-9):450-8. 


\section{List of Tables}

Table 1 Macro mechanical properties of Yunnan sandstone. $\rho$ - density; $E$ - Young's modulus; $v$ - Poisson's ratio; $\sigma_{c}$ - uniaxial compressive strength; $\sigma_{T}$ - tensile strength; Error - the ratio of the difference between the measured value and the average value.

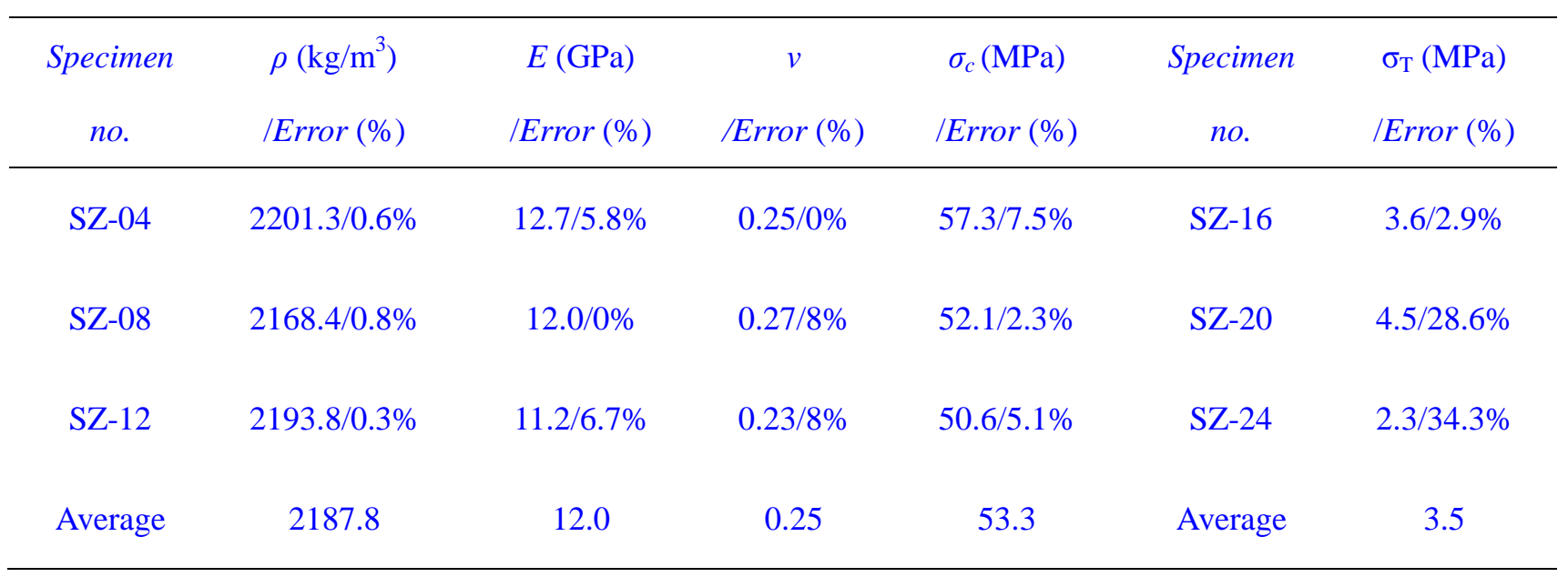

Table 2. The mesoscale physical properties used to study the mechanical behavior (found through calibration). $E-$ Young's modulus; $v$ - Poisson's ratio; $K_{n}-$ normal stiffness of the sub-contact; $K_{s}-$ shear stiffness of the sub-contact. $J_{T}$ - tensile strength of the sub-contact; $J_{c}$ - cohesion of the sub-contact; $\varphi$ - friction angle of the sub-contact; $\varphi_{r}$ - residual friction angle of the sub-contact.

\begin{tabular}{cccccccc}
\hline$E / \mathrm{GPa}$ & $v$ & $K_{n} / \mathrm{GPa} \cdot \mathrm{mm}^{-1}$ & $K_{n} / K_{s}$ & $J_{T} / \mathrm{MPa}$ & $J_{c} / \mathrm{MPa}$ & $\phi /^{\circ}$ & $\varphi_{r} /{ }^{\circ}$ \\
\hline 12 & 0.27 & 40 & 2 & 7.6 & 31.2 & 27 & 6 \\
\hline
\end{tabular}


Table 3. Summary of the conventional uniaxial creep simulations at different stress levels.

\begin{tabular}{|c|c|c|c|c|c|c|}
\hline \multirow{2}{*}{$\begin{array}{c}\text { Short-term } \\
\text { failure } \\
\text { strength } / \mathrm{MPa}\end{array}$} & \multirow{2}{*}{$\begin{array}{l}\text { Creep } \\
\text { stress } \\
/ \mathrm{MPa}\end{array}$} & \multirow{2}{*}{$\begin{array}{l}\text { Percentage of the } \\
\text { short-term failure } \\
\text { stress }\end{array}$} & \multirow{2}{*}{$\begin{array}{l}\text { Minimum } \\
\text { axial strain } \\
\text { rate } / \mathrm{s}^{-1}\end{array}$} & \multirow{2}{*}{$\begin{array}{l}\text { Minimum } \\
\text { lateral strain } \\
\text { rate } / \mathrm{s}^{-1}\end{array}$} & \multicolumn{2}{|c|}{ Time to failure } \\
\hline & & & & & $\begin{array}{c}\text { Simulation } \\
/ \mathrm{s}\end{array}$ & $\begin{array}{c}\text { Laboratory } \\
\qquad / \mathrm{s}\end{array}$ \\
\hline \multirow{5}{*}{52.1} & 36.4 & $70 \%$ & $1.78 \times 10^{-11}$ & $3.37 \times 10^{-11}$ & $1.36 \times 10^{6}$ & -* \\
\hline & 41.6 & $80 \%$ & $2.11 \times 10^{-10}$ & $4.51 \times 10^{10}$ & $3.14 \times 10^{5}$ & $3.14 \times 10^{5}$ \\
\hline & 44.2 & $85 \%$ & $1.13 \times 10^{-9}$ & $3.75 \times 10^{-9}$ & $1.15 \times 10^{5}$ & $9.72 \times 10^{4}$ \\
\hline & 46.8 & $90 \%$ & $9.29 \times 10^{-9}$ & $2.42 \times 10^{-8}$ & $2.92 \times 10^{4}$ & $4.45 \times 10^{4}$ \\
\hline & 49.4 & $95 \%$ & $5.95 \times 10^{-8}$ & $1.42 \times 10^{-7}$ & $1.70 \times 10^{4}$ & $1.60 \times 10^{4}$ \\
\hline
\end{tabular}

*Note: Due to the very low strain rate, the experiment in which the sample was held at $70 \%$ of the short-term strength was stopped after $100 \mathrm{~h}$. 


\section{List of Figure Captions}

Fig. 1. (a) Voronoi tessellation designed to replicate the grain scale properties of Yunnan sandstone shown in (b). (b) Scanning electron microscope picture of Yunnan sandstone.

Fig. 2. (a) The 3D numerical specimen (50 $\mathrm{mm}$ in diameter and $100 \mathrm{~mm}$ in length) used in this study. (b) 3D view of the cylindrical numerical specimen showing the position of the grid points within the specimen used to determine the axial and lateral strain (see text for details) and the area (red polyhedral grains) where the axial stress is calculated. We use the same method of stress and strain determination presented in Ghazvinian et al. (2014).

Fig. 3. Stress-strain graph showing the constitutive behavior of contact between the grains. (a) Stress-strain graph in the normal direction. (b) Stress-strain graph in the shear direction. Contacts can fail (open) or slide. $\mathrm{K}_{\mathrm{n}}-$ normal stiffness of the sub-contact; $K_{s}-$ shear stiffness of the sub-contact.

Fig. 4. Degradation rate relations for the 3DEC-GBM. $\sigma_{0}$ - threshold stress below which stress corrosion does not occur; $\sigma_{\mathrm{c}}-$ the peak strength.

Fig. 5. Experimental and simulative stress-strain curves (axial and lateral strain) for a cylindrical laboratory specimen (100 $\mathrm{mm}$ in length and $50 \mathrm{~mm}$ in diameter). The solid blue line and dashed red line are experimental and simulative stress-strain curves, respectively. In addition, the dashed pink line is the experimental stress-strain curve with the initial non-linear part of the stress-strain curve removed (see text for details).

Fig. 6. Macroscopic fracture patterns produced by laboratory experiments and 3DEC-GBM modeling. (a) Image of a numerically failed sample (50 $\mathrm{mm}$ in diameter and $100 \mathrm{~mm}$ in height). (b) Photograph of an experimentally failed sample (50 $\mathrm{mm}$ in diameter and $100 \mathrm{~mm}$ in height).

Fig. 7. Two sample numerical models describing microcrack time-dependent growth between grains. (a) The 3D numerical specimen comprised an assemblage of Voronoi polyhedra grains. (b) Randomly selected two adjacent Voronoi polyhedra grains. (c) The Voronoi polyhedra grain simplified into the cube grain (2.5 $\mathrm{mm}$ in length). The 
length of the pre-existing crack is $0.2 \mathrm{~mm}$, and the pre-existing crack is composed of many sub-contacts with no strength. (d) The tensile stress condition. (e) The shear stress condition.

Fig. 8. Influence of the subcritical parameters on time-to-failure of the model. (a) tension, (b) shear.

Fig. 9. 2D slice of the cube grain models (see Fig. 7 and text for details) showing microcrack growth. (a) Microcrack growth and stress nephogram for different stages of deformation under 3.0 MPa tensile load. (b) Microcrack growth and stress nephogram for different stages of deformation under 4.5 MPa shear load.

Fig. 10. (a) Modeled axial strain-time curves for a cylindrical numerical specimen (100 $\mathrm{mm}$ in length and $50 \mathrm{~mm}$ in diameter). The evolution of damage as a function of time (see text for details) is shown by the blue curve. The evolution of axial strain rate as a function of time (see text for details) is shown by the red curve. (b) Lateral axial strain and volume strain as a function of time at a constant stress of $41.6 \mathrm{MPa}$.

Fig. 11. Modeled axial strain-time curves for a cylindrical numerical specimen $(100 \mathrm{~mm}$ in length and $50 \mathrm{~mm}$ in diameter) (the same specimen shown in Fig. 10). The dashed red line is the experimental axial strain-time curve. The evolution of the cumulative numbers of tensile and shear cracks as a function of time (see text for details) is shown by the blue curves.

Fig. 12. Modeled uniaxial creep curves for sandstone under different constant uniaxial stresses (from 36.4 to 49.4 MPa; Table 3). (a) Strain-time (creep) curves for the studied sandstone. (b) Lateral strain-time curves for the studied sandstone. (c) Damage-time curves (see text for the definition of "damage") for the studied sandstone.

Fig. 13. Minimum axial and lateral creep strain rate as a function of axial stress for the simulated uniaxial creep tests shown in Fig. 12. 
(a)

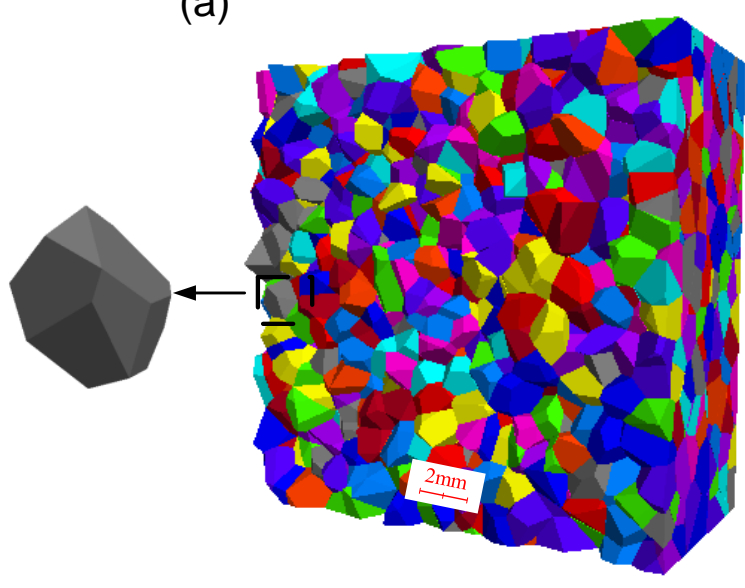

(b)

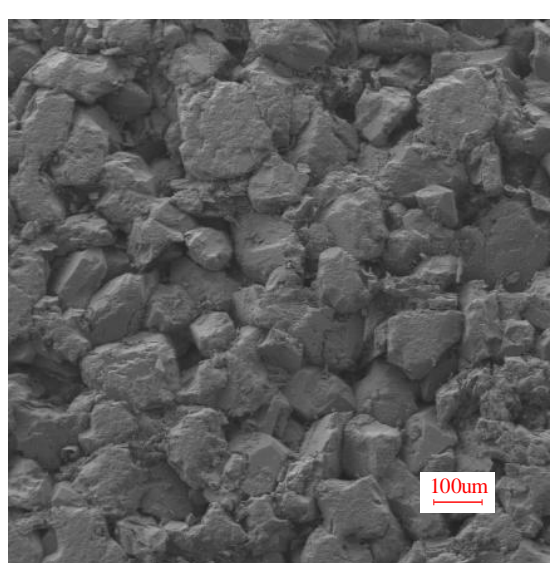

Fig. 1 
(a)

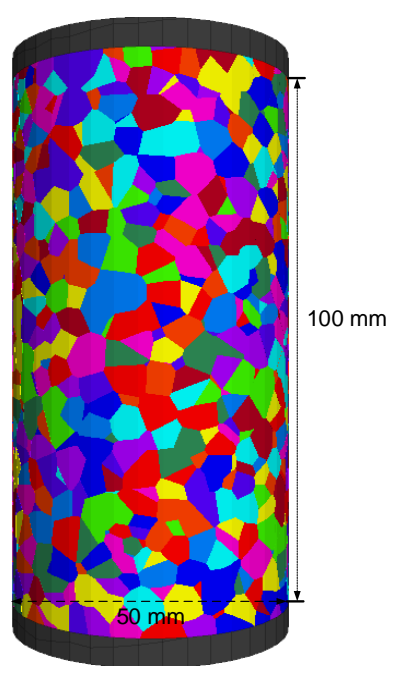

(b)

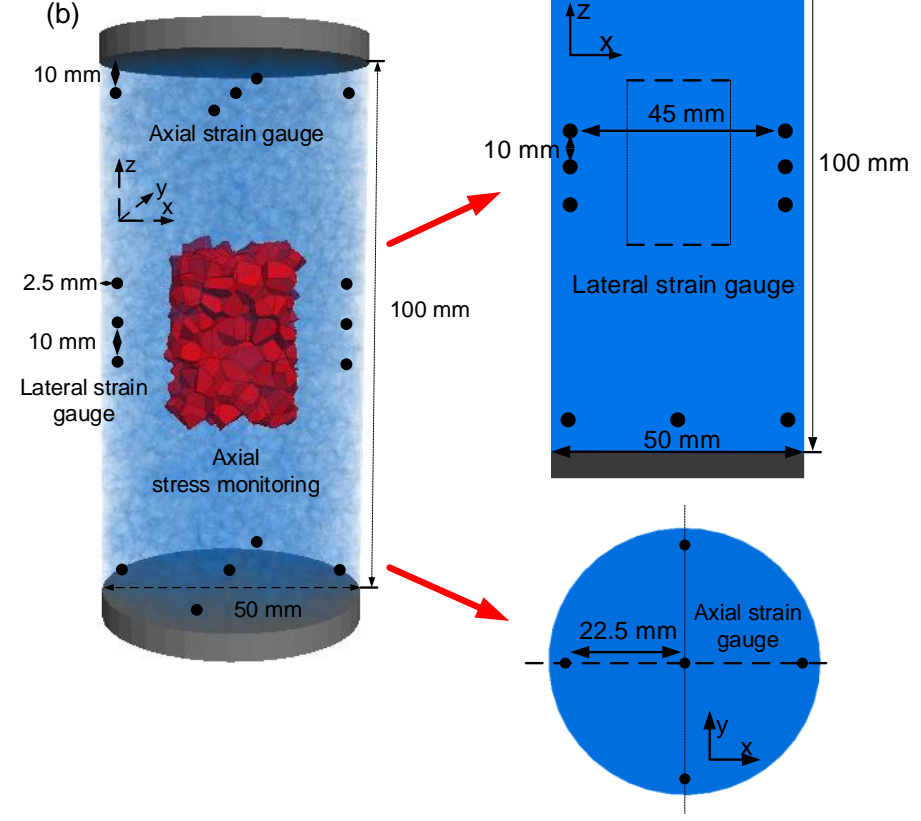

Fig. 2 

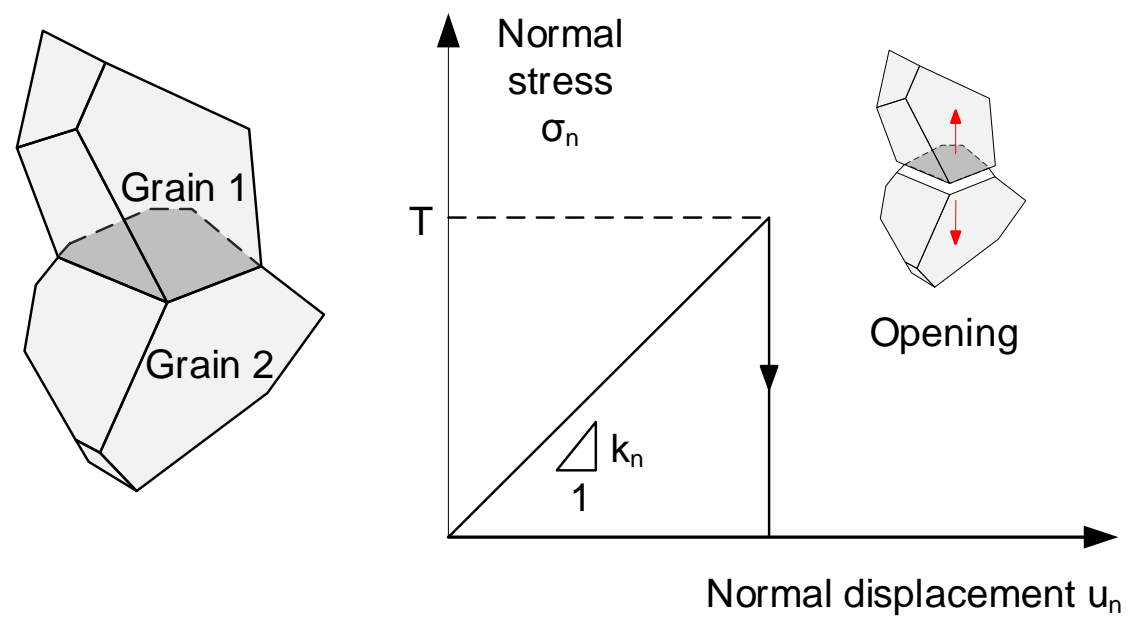

(a)

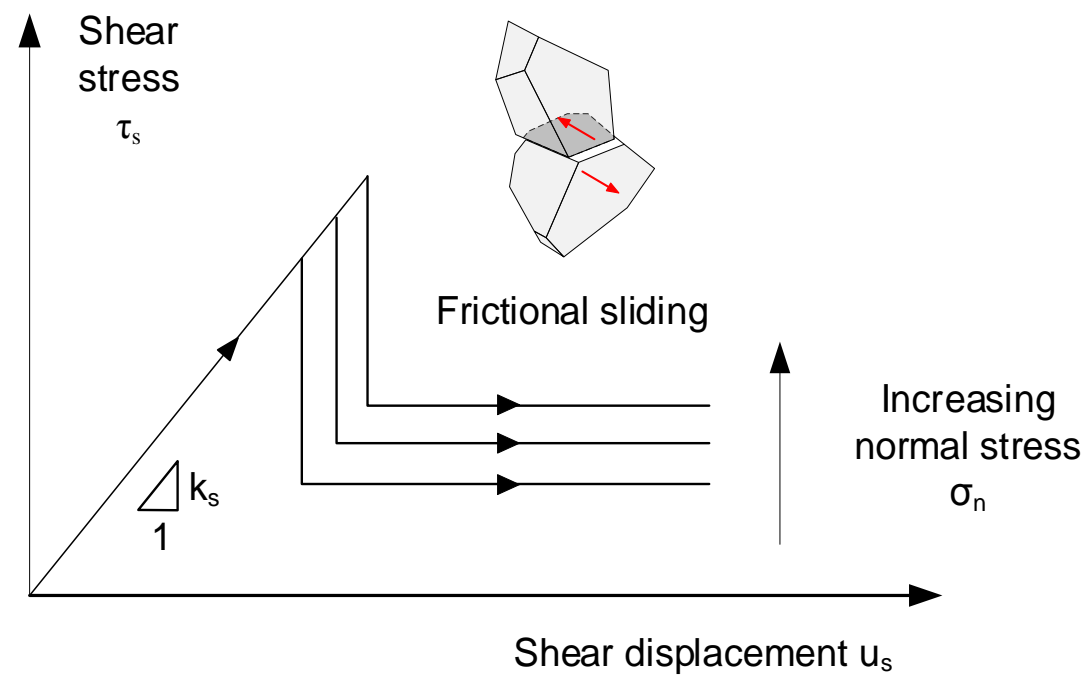

(b)

Fig. 3 


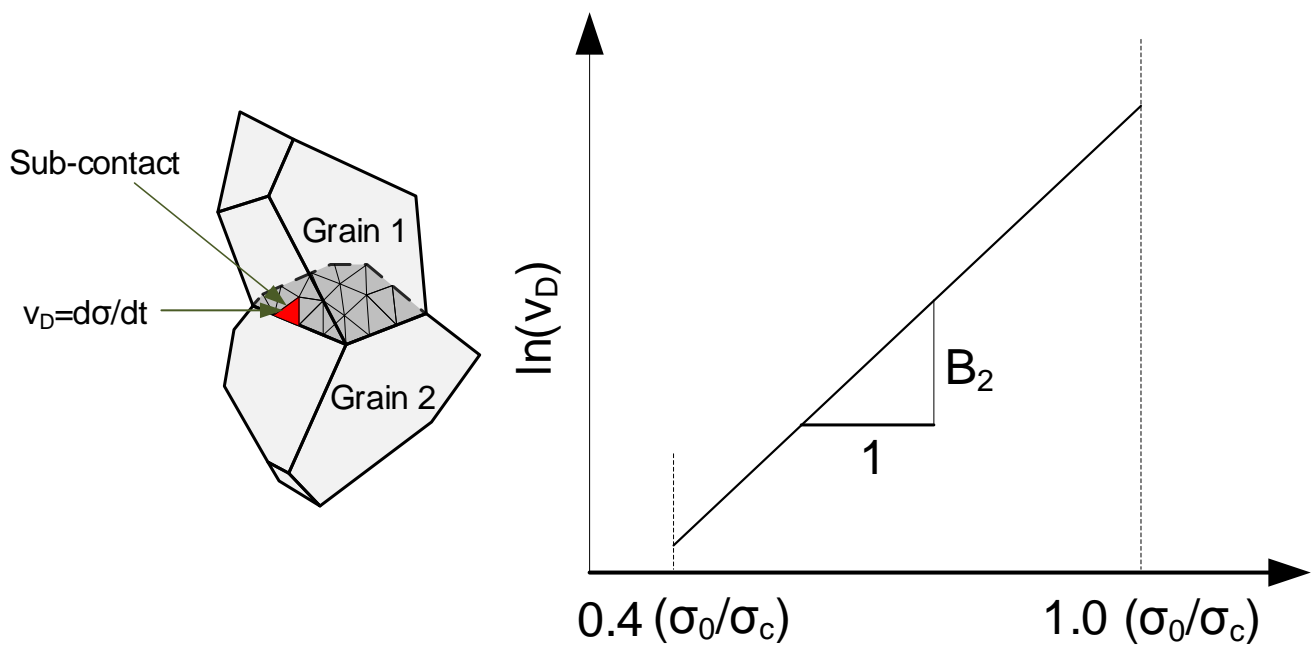

Fig. 4 


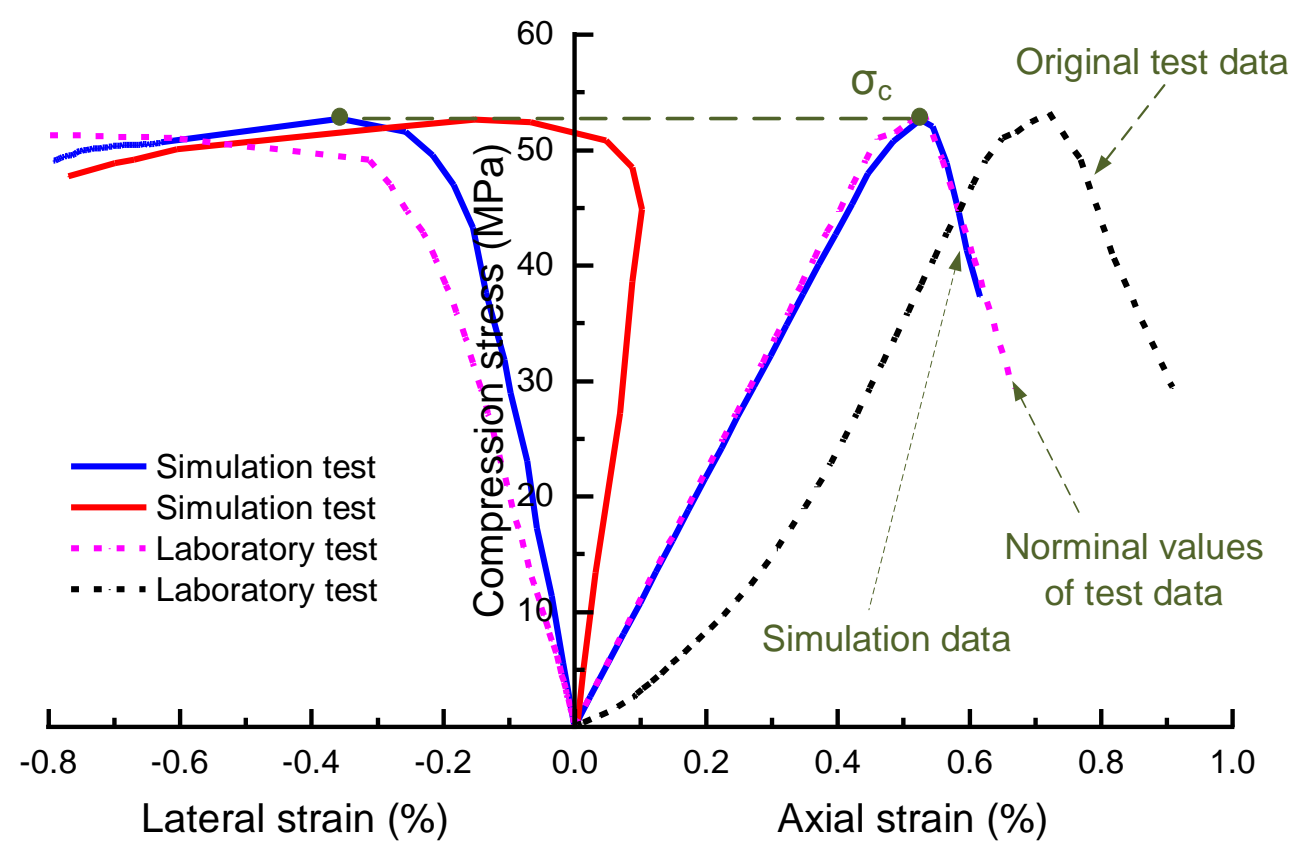

Fig. 5 
(a)

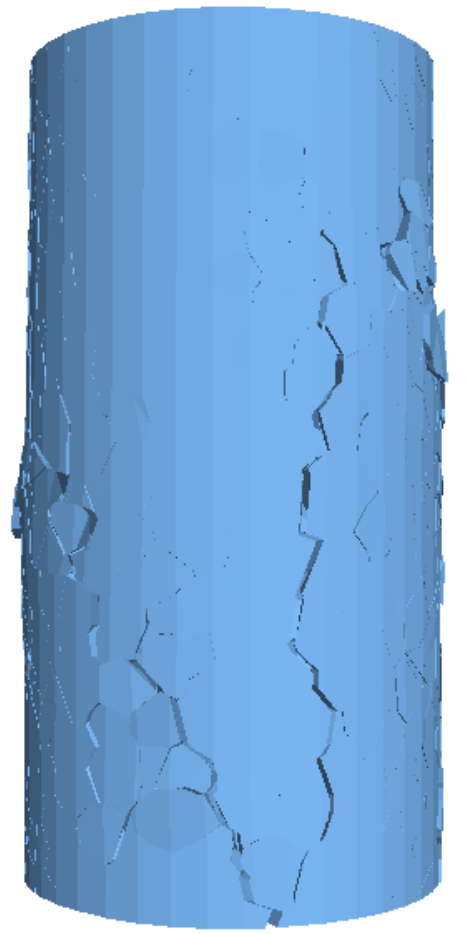

(b)

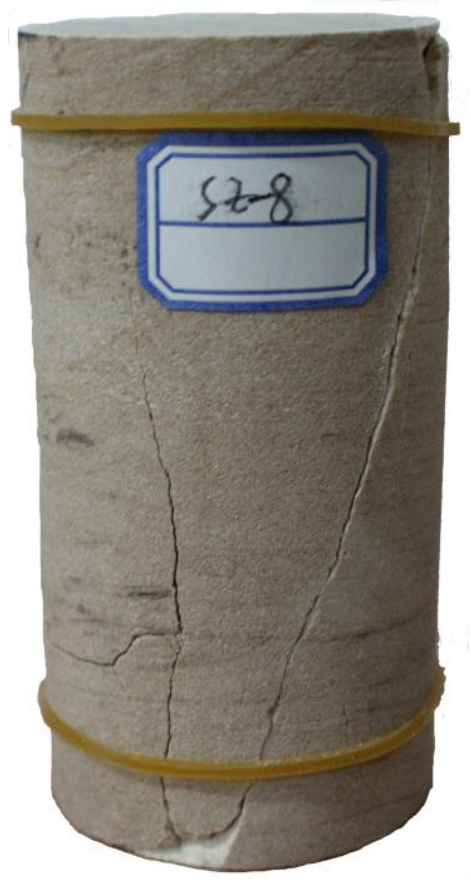

Fig. 6 
(a)
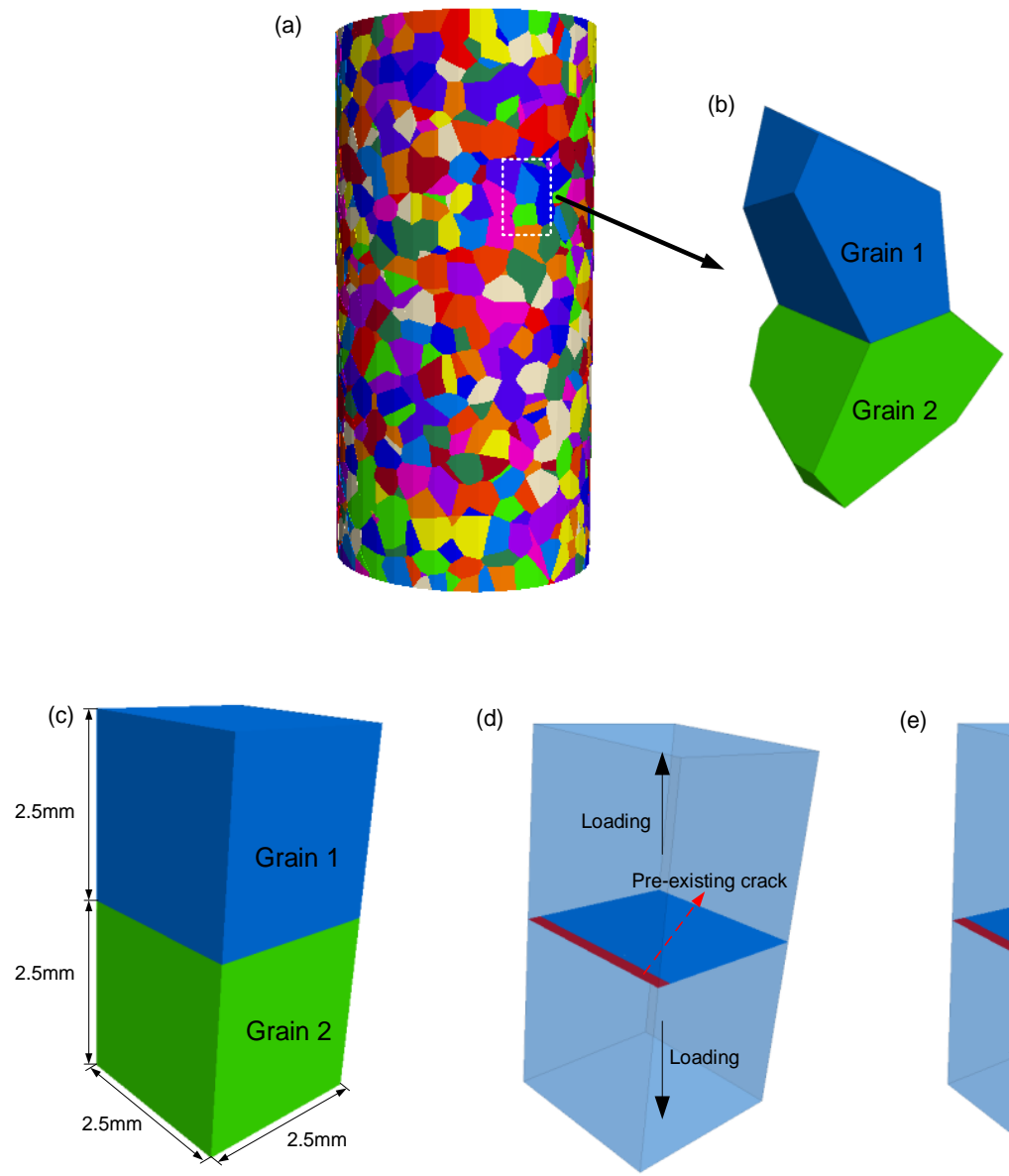

(d)

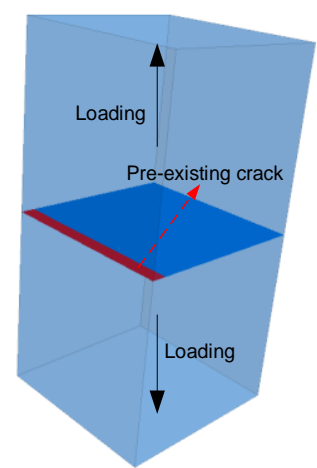

(e)

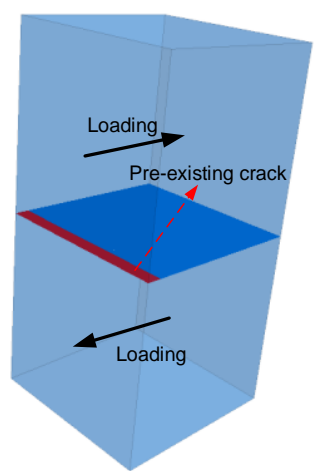

Fig. 7 

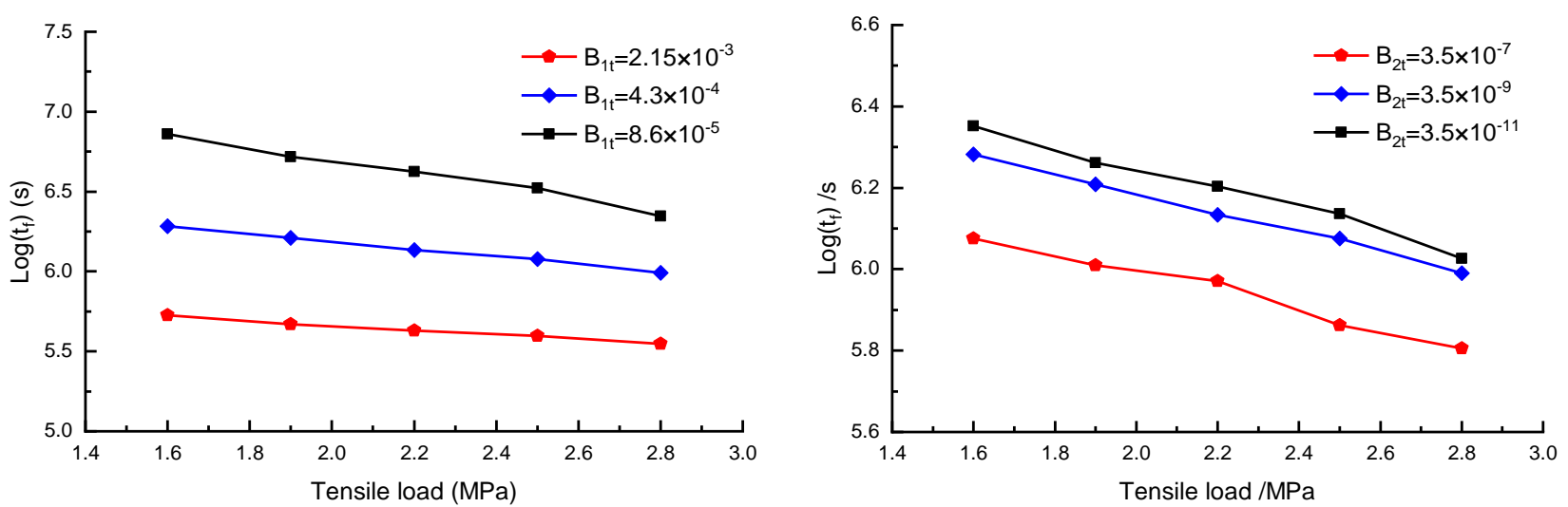

(a)
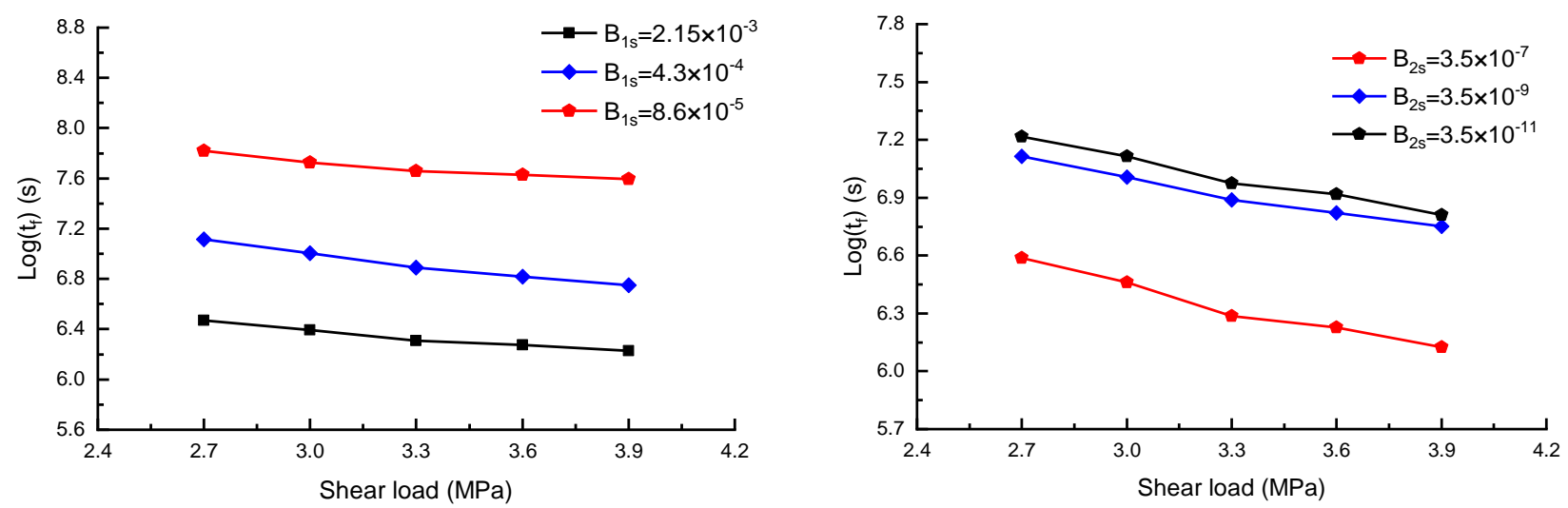

(b )

Fig. 8 


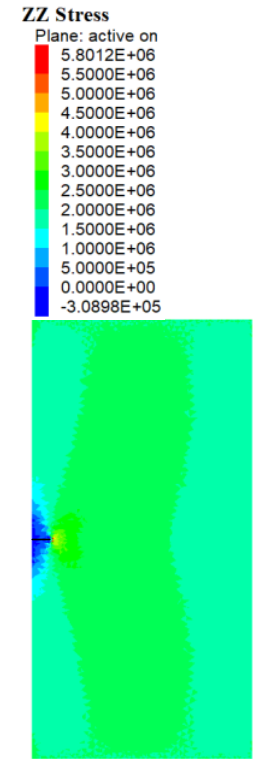

$9.3 \times 10^{6} \mathrm{~s}$

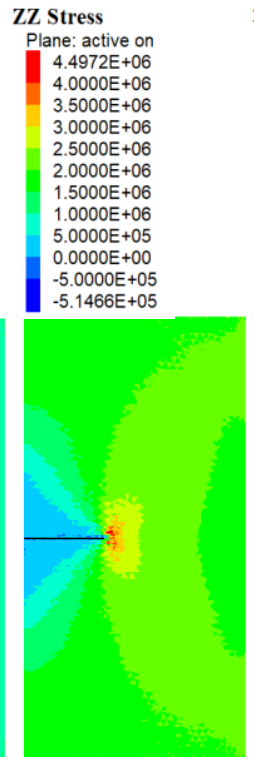

$1.16 \times 10^{6} \mathrm{~s}$

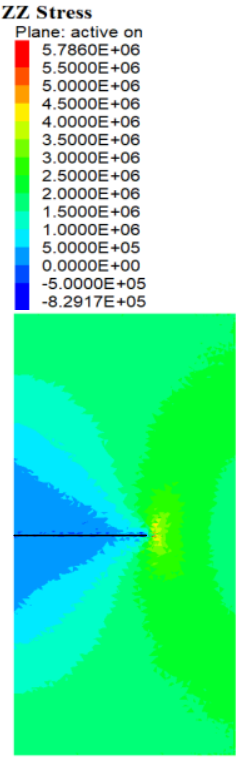

$1.22 \times 10^{6} \mathrm{~s}$

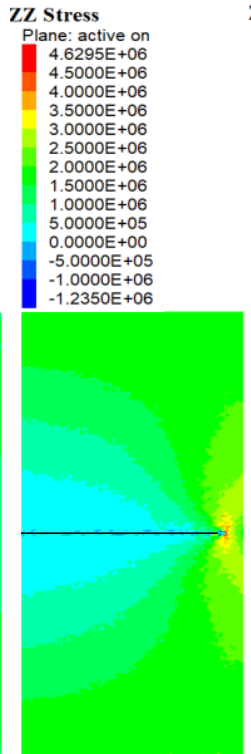

$1.28 \times 10^{6} \mathrm{~s}$

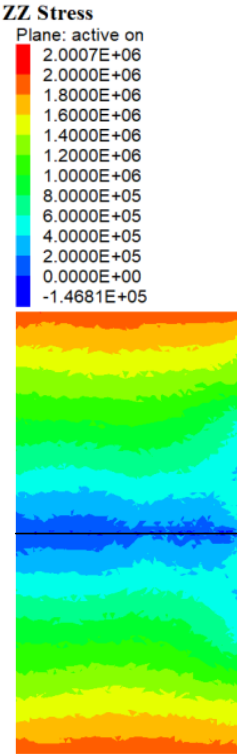

$1.36 \times 10^{6} \mathrm{~s}$

(a)

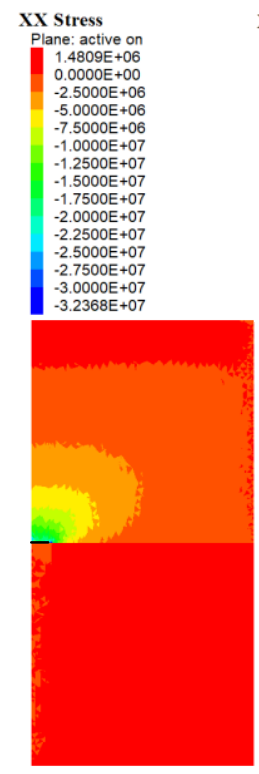

$5.9 \times 10^{6} \mathrm{~s}$

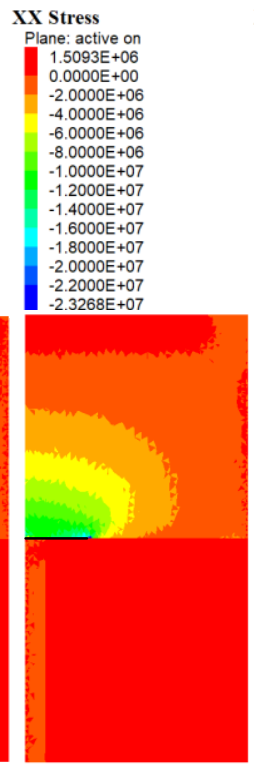

$6.9 \times 10^{6} s$

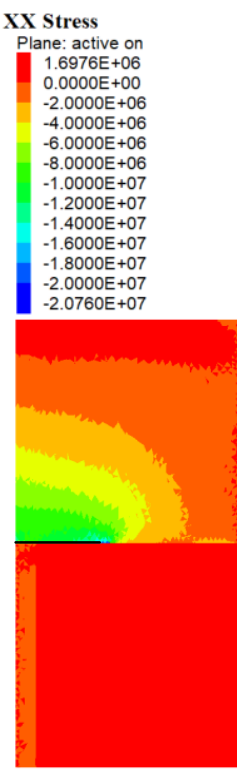

$7.2 \times 10^{6} \mathrm{~s}$

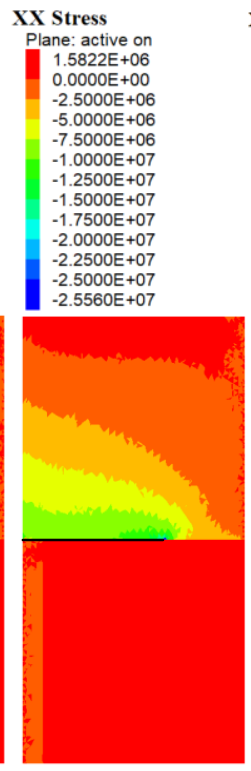

$7.3 \times 10^{6} \mathrm{~s}$

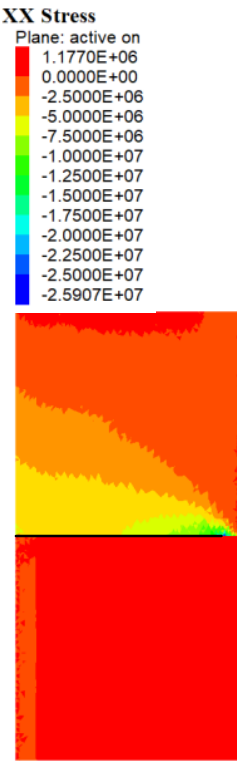

$7.4 \times 10^{6} \mathrm{~s}$

(b)

Fig. 9 


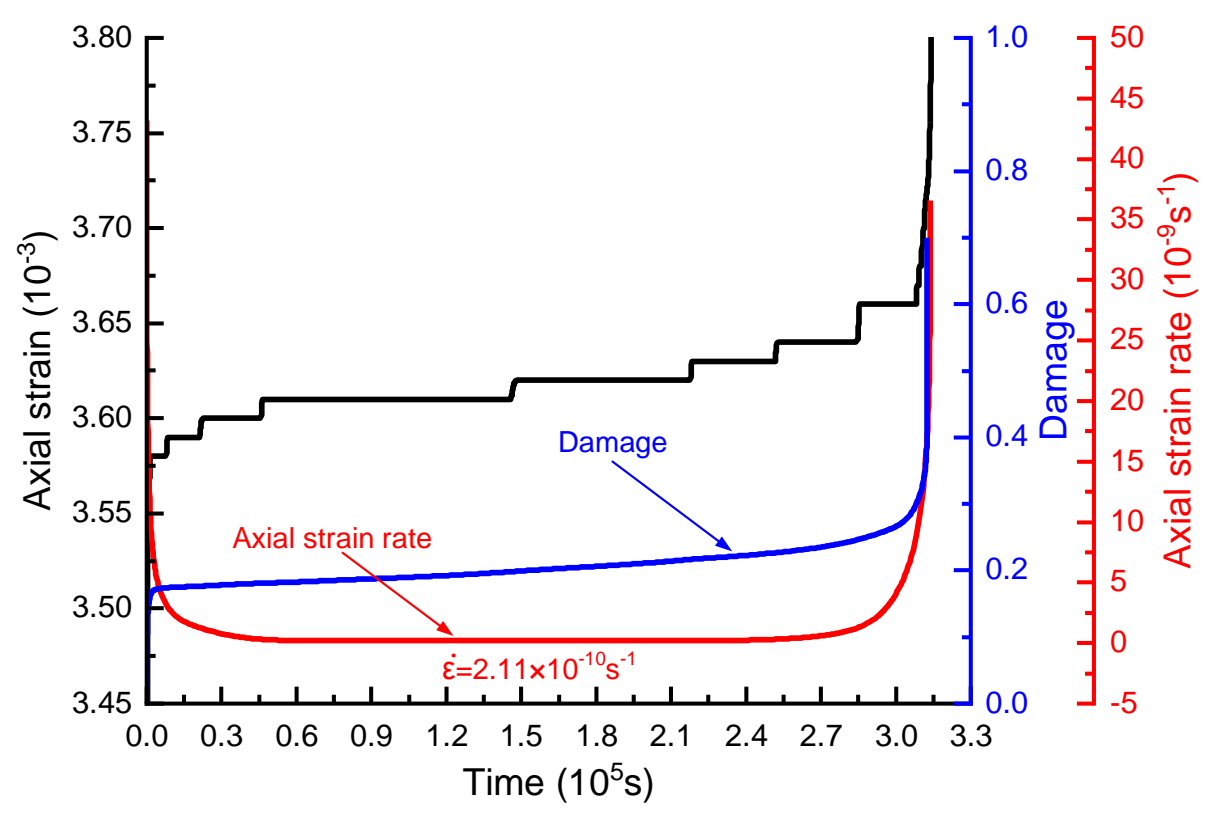

(a)

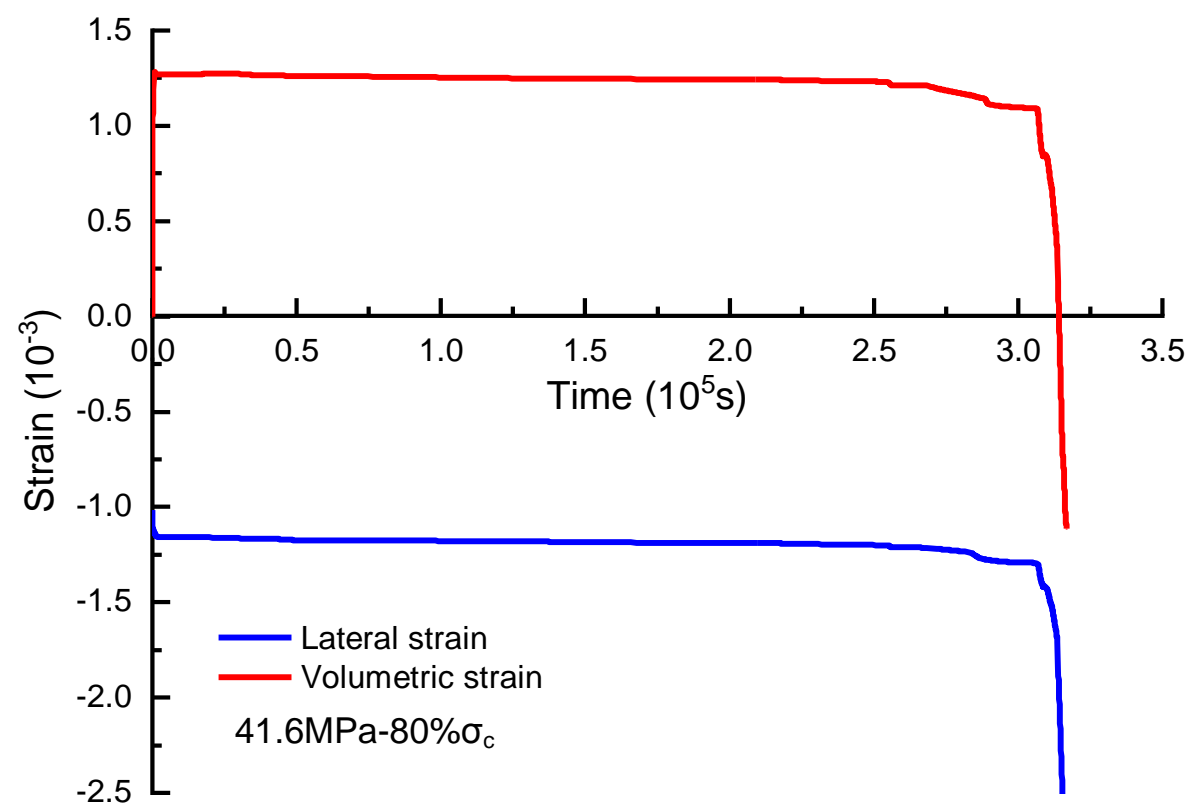

(b)

Fig. 10 


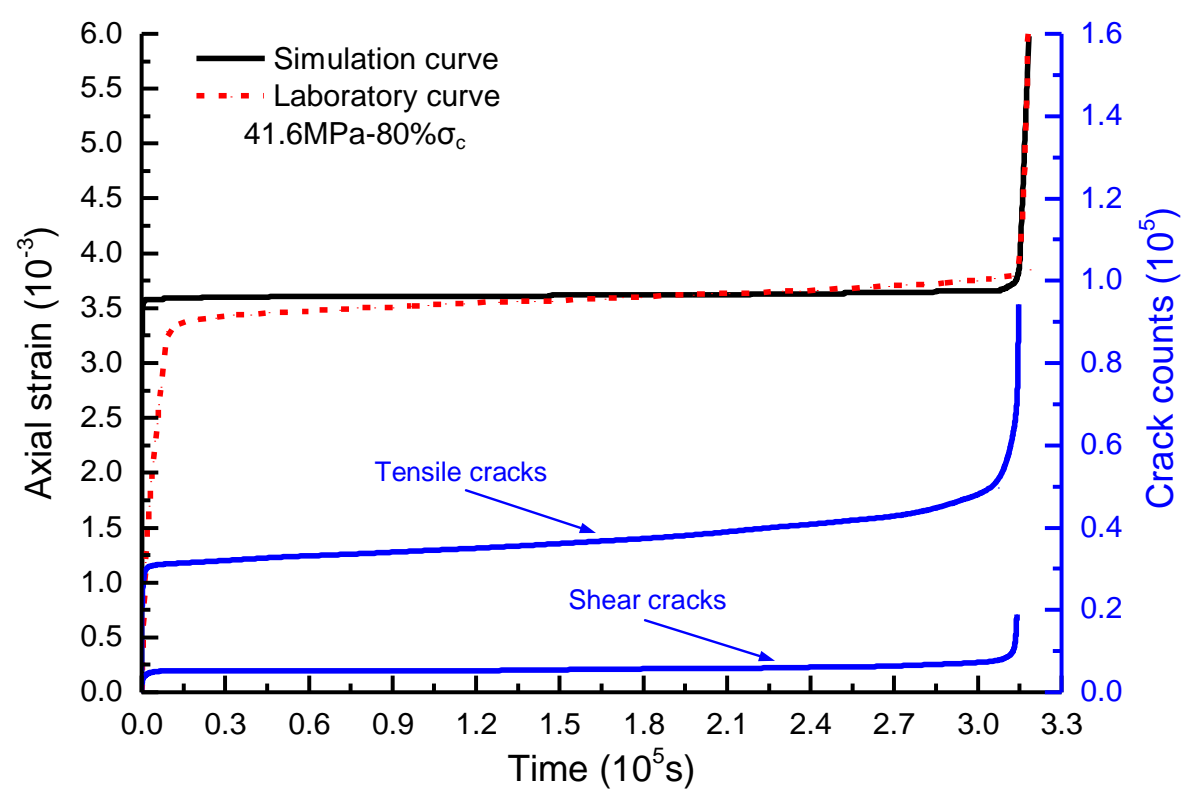

Fig. 11 


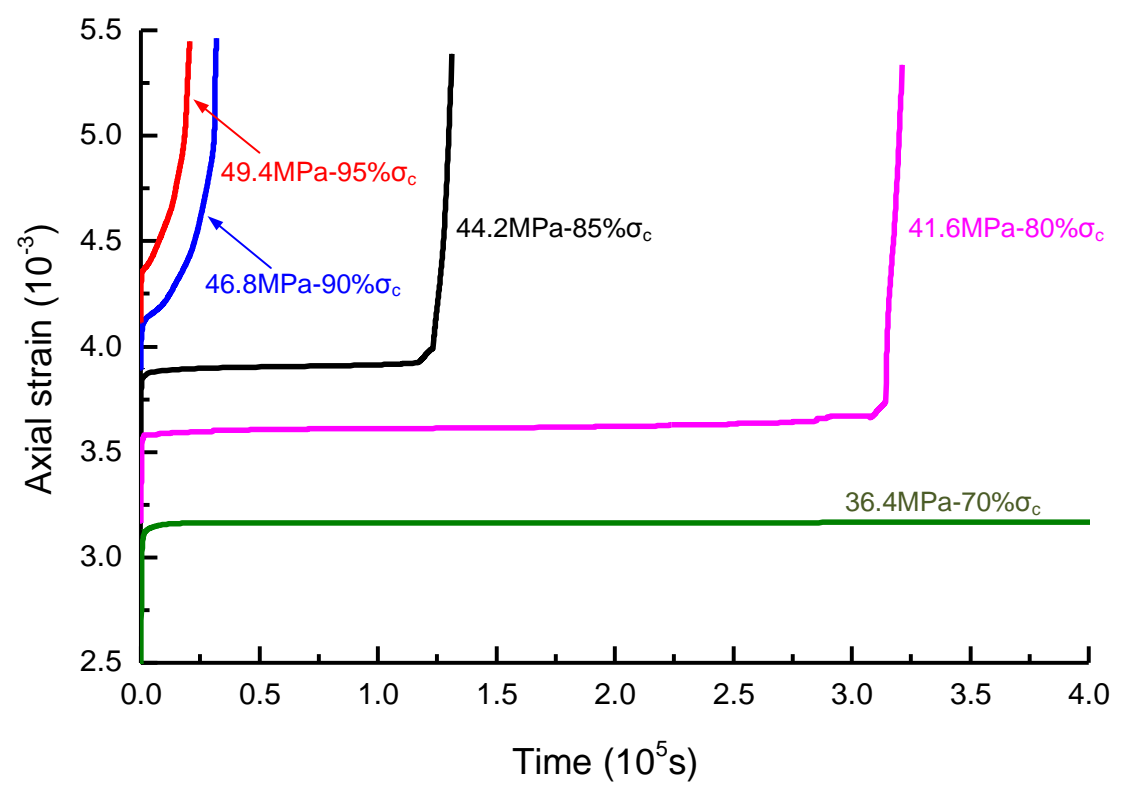

(a)

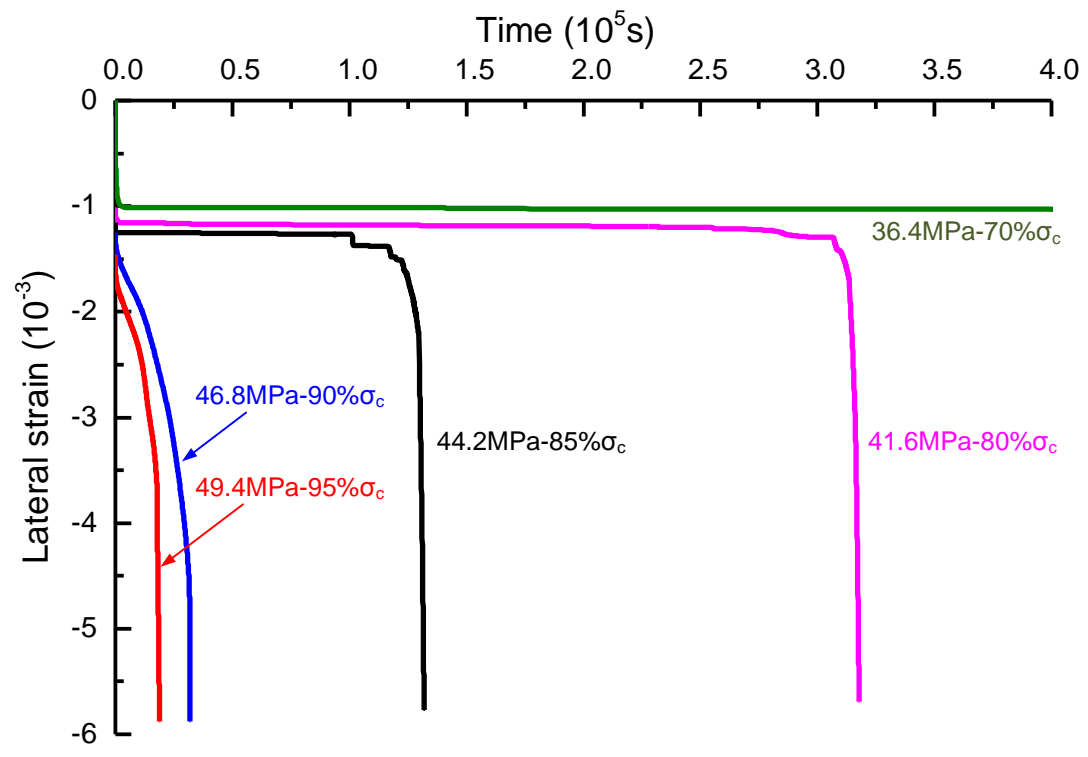

(b) 


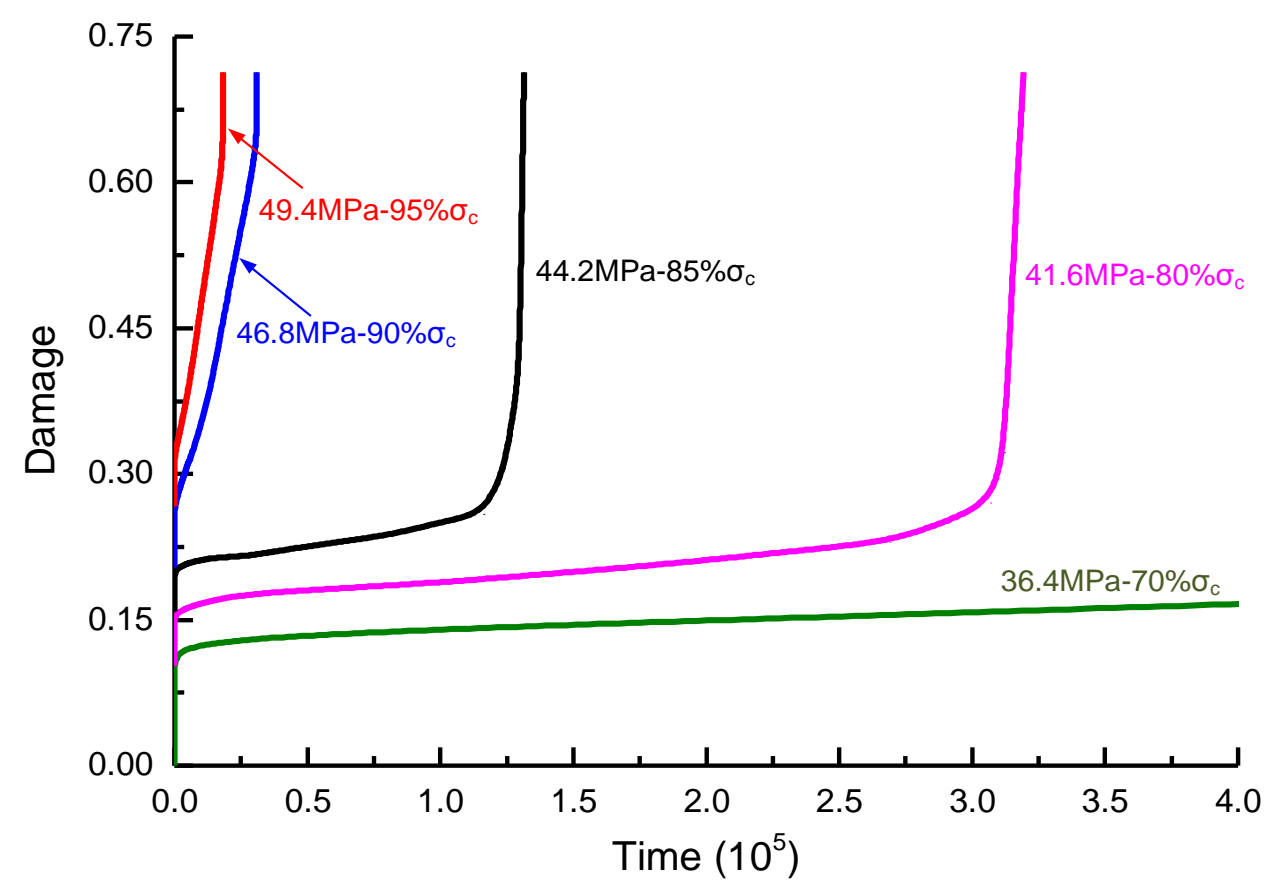

(c)

Fig. 12 


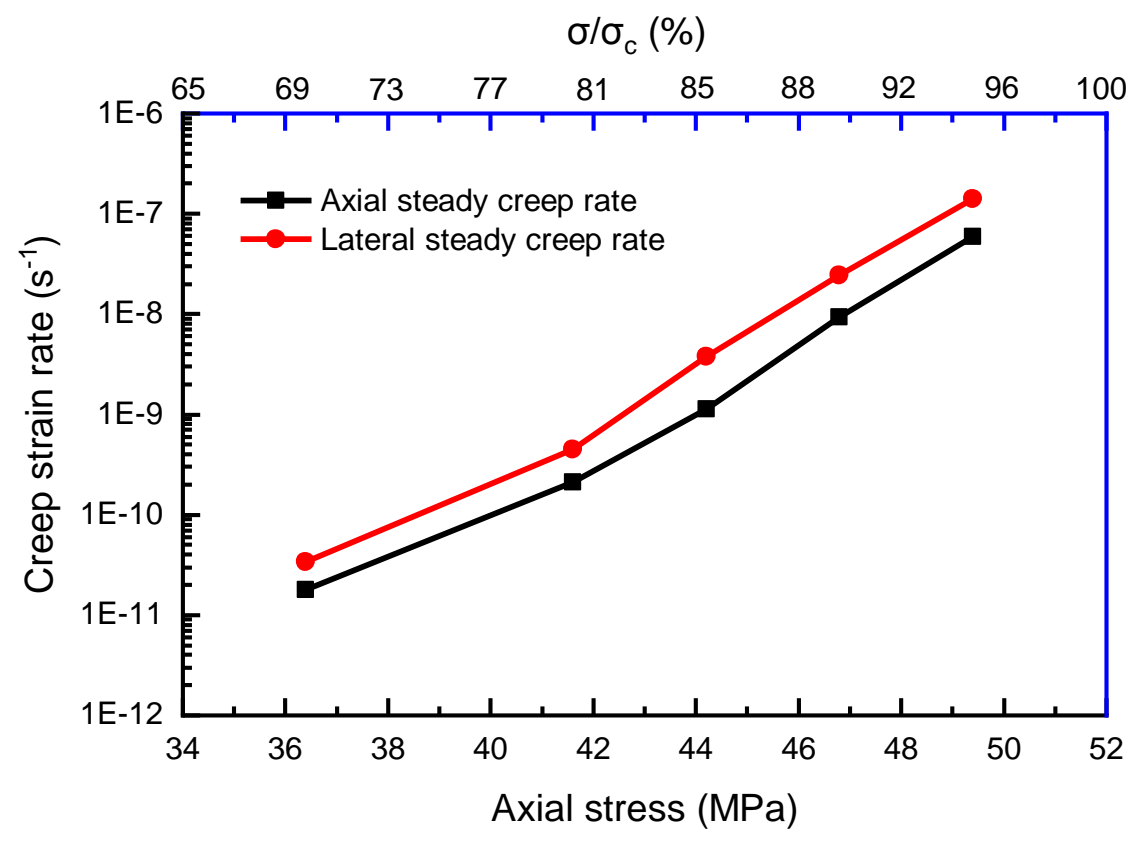

Fig. 13 